\title{
Material and Interaction Properties of Selected Grains ANd Oilseeds for Modeling Discrete Particles
}

\author{
J. M. Boac， M. E. Casada， R. G. Maghirang, J. P. Harner III
}

\begin{abstract}
Experimental investigations of grain flow can be expensive and time consuming, but computer simulations can reduce the large effort required to evaluate the flow of grain in handling operations. Published data on material and interaction properties of selected grains and oilseeds relevant to discrete element method (DEM) modeling were reviewed. Material properties include grain kernel shape, size, and distribution; Poisson's ratio; shear modulus; and density. Interaction properties consist of coefficients of restitution, static friction, and rolling friction. Soybeans were selected as the test material for DEM simulations to validate the model fundamentals using material and interaction properties. Single-and multi-sphere soybean particle shapes, comprised of one to four overlapping spheres, were compared based on DEM simulations of bulk properties (bulk density and bulk angle of repose) and computation time. A single-sphere particle model best simulated soybean kernels in the bulk property tests. The best particle model had a particle coefficient of restitution of 0.6, particle coefficient of static friction of 0.45 for soybean-soybean contact ( 0.30 for soybean-steel interaction), particle coefficient of rolling friction of 0.05, normal particle size distribution with standard deviation factor of 0.4, and particle shear modulus of $1.04 \mathrm{MPa}$.
\end{abstract}

Keywords. Barley, Canola, Corn, Discrete element method, Interaction properties, Material properties, Multi-sphere particle, Oats, Rice, Simulation, Single-sphere particle, Sorghum, Soybeans, Sunflower, Wheat.

$\mathrm{P}$ hysical characteristics are important in analyzing the behavior of grains in handling operations (Mohsenin, 1986). Bulk handling behavior of the grains can be studied experimentally, but large-scale investigations of grain flow can be expensive and time consuming. On the other hand, computer simulations can reduce the large effort required to evaluate the flow of grain in handling operations.

Recently, grain segregation and identity preservation operations have become important as grain handlers respond to an increased use of specialty grain (Berruto and Maier, 2001; Herrman et al., 2001, 2002). However, limited studies have been conducted to quantify the commingling that may occur during grain handling in grain elevators (Hurburgh, 1999; In-

Submitted for review in October 2009 as manuscript number FPE 8236; approved for publication by the Food \& Process Engineering Institute Division of ASABE in June 2010. Presented at the 2009 ASABE Annual Meeting as Paper No. 097166.

Mention of trade names or commercial products in this article is solely for the purpose of providing specific information and does not imply recommendation or endorsement by the USDA.

The authors are Josephine M. Boac, ASABE Member Engineer, Postdoctoral Research Associate, Department of Biological and Agricultural Engineering, Kansas State University, Manhattan, Kansas; Mark E. Casada, ASABE Member Engineer, Lead Scientist, Agricultural Engineer, USDA-ARS Center for Grain and Animal Health Research, Engineering and Wind Erosion Research Unit, Manhattan, Kansas; Ronaldo G. Maghirang, ASABE Member Engineer, Professor, and Joseph P. Harner III, ASABE Member Engineer, Professor and Department Head, Department of Biological and Agricultural Engineering, Kansas State University, Manhattan, Kansas. Corresponding author: Mark E. Casada, USDA-ARS Center for Grain and Animal Health Research, Engineering and Wind Erosion Research Unit, 1515 College Ave., Manhattan, KS 66502; phone: 785-776-2758; fax: 785-537-5550; e-mail: casada@ksu.edu. gles et al., 2003, 2006) and with farm equipment (Greenlees and Shouse, 2000; Hirai et al., 2006; Hanna et al., 2006). Limited data on grain commingling during handling in grain elevators (Ingles et al., 2003, 2006) make it difficult to accurately predict levels of impurities that would propagate through grain handling systems. Thus, a validated mechanistic model for predicting grain commingling in various types of elevator equipment will be valuable for extending the knowledge of grain commingling beyond current experimental studies.

Different modeling techniques such as continuum models and discrete element models (Wightman et al., 1998) have potential to simulate grain commingling in elevator equipment. The discrete element method (DEM) is considered one of the most promising techniques to simulate movement of individual particles (Wightman et al., 1998) such as grain kernals in bucket elevator equipment. DEM is an explicit numerical scheme in which particle interaction is monitored contact by contact and the motion of individual particles is modeled (LoCurto et al., 1997b). This explicit scheme requires small time steps, resulting in potential problems with developing realistic models that can run in a reasonable time on available computers. The model must use a critical time increment that achieves stability and simulates the true physics with a manageable number of calculations (O'Sullivan and Bray, 2004; Li et al., 2005).

Relevant grain physical properties must be known to accurately simulate grain handling operations. The objectives of this study were (1) to review published physical properties of grains and oilseeds needed to model grain commingling in DEM, and (2) to develop and validate an appropriate particle model for one test seed, soybeans, based on these physical properties. Soybeans were chosen as the test seed due to their almost spherical shape for simplicity of modeling. Addition- 
Table 1. Range of published physical properties of grains and oilseeds.

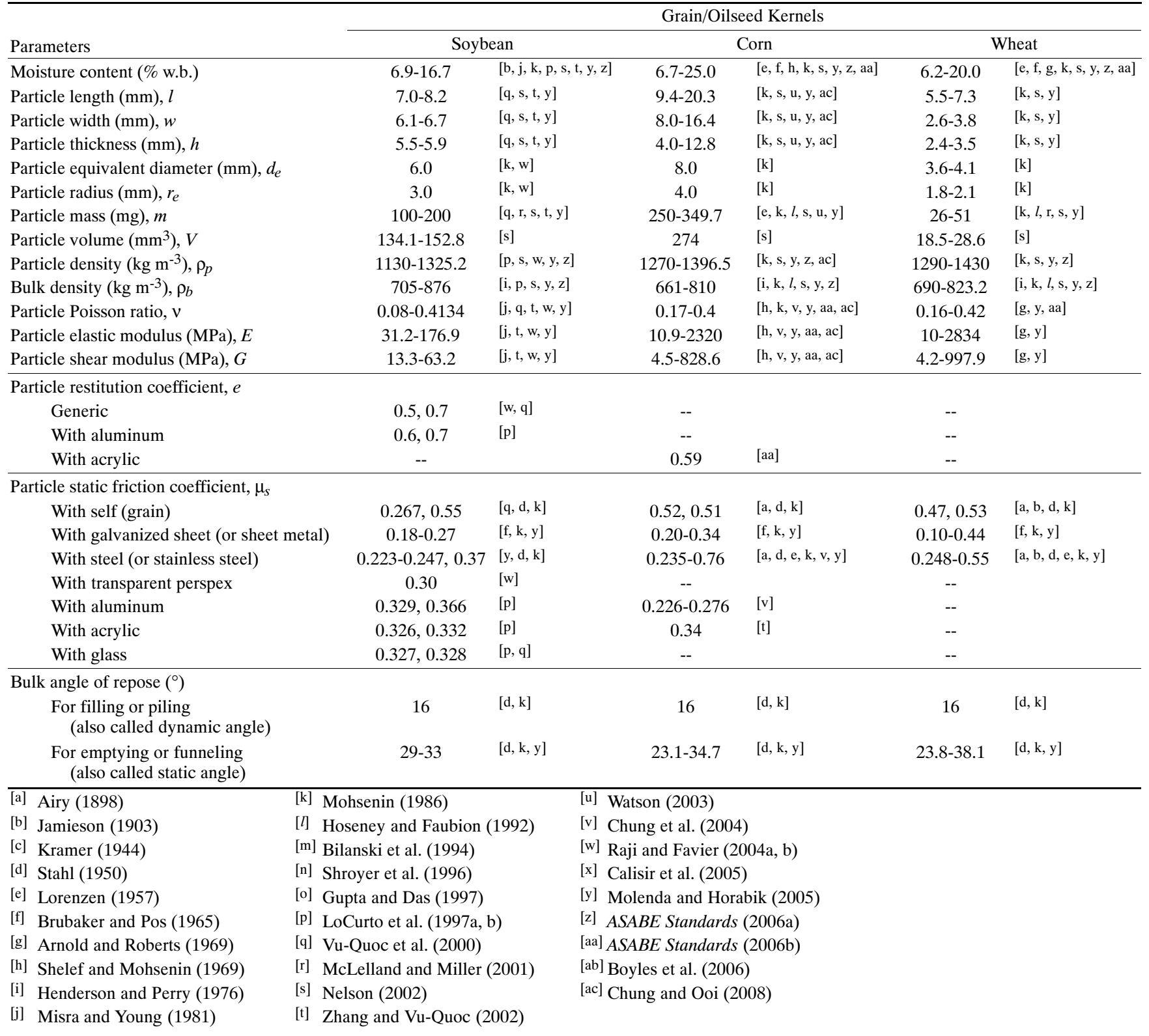

ally, other major seeds with non-spherical shapes (e.g., corn, wheat) were also reviewed in this study. Their physical properties can be used for future DEM modeling.

\section{Physical Properties of Grains and OILSEEDS}

Different DEM models have used varying parameters for simulation modeling. The most widely used parameters can be divided into two categories: material properties and interaction properties (Mohsenin, 1986; Vu-Quoc et al., 2000; Raji and Favier, 2004a, 2004b). Material properties may be defined as intrinsic characteristics of the particle (i.e., grain kernels) that is being modeled. Among material properties critical as inputs in DEM modeling are shape, size distribution, density, Poisson's ratio, and shear modulus. Interaction properties are characteristics exhibited by the particle in relation to its contact with boundaries, surfaces, and other (or same) particles. Interaction properties, vital in DEM modeling, are coefficients of restitution, and static and rolling friction (LoCurto et al., 1997b; Chung et al., 2004). Grain material and interaction properties available in the literature are summarized in table 1 .

\section{Particle Shape and Particle Size}

Shape and size are inseparable physical properties in a grain kernel. In defining shape, some dimensional parameters of the grain must be measured. Mohsenin (1986) and Nelson (2002) reported measuring three orthogonally oriented dimensions of 50 kernels randomly selected from a grain lot to determine kernel shape and size. The volume was taken as one of the parameters defining kernel shape, and the three mutually perpendicular axes were taken as a measure of kernel size. 
Table 1 (continued). Range of published physical properties of grains and oilseeds.

\begin{tabular}{|c|c|c|c|c|c|c|c|}
\hline \multirow{3}{*}{$\begin{array}{l}\text { Parameters } \\
\text { Moisture content (\% w.b.) }\end{array}$} & & \multicolumn{6}{|c|}{ Grain/Oilseed Kernels } \\
\hline & \multicolumn{3}{|c|}{ Grain Sorghum } & \multicolumn{2}{|l|}{ Rice } & \multicolumn{2}{|l|}{ Barley } \\
\hline & & $9.2-11.2$ & {$[\mathrm{k}, \mathrm{s}, \mathrm{z}]$} & $8.6-15.7$ & {$[\mathrm{c}, \mathrm{d}, \mathrm{k}, \mathrm{s}, \mathrm{z}]$} & $7.5-20.0$ & {$[\mathrm{e}, \mathrm{f}, \mathrm{k}, \mathrm{s}, \mathrm{y}, \mathrm{z}]$} \\
\hline Particle length (mm), $l$ & & $4.3,4.5$ & {$[\mathrm{k}, \mathrm{s}]$} & $5.3-8.9^{* *}, 7.6-9.8$ & {$[\mathrm{k}, \mathrm{s}]$} & 7.9-10.9 & {$[\mathrm{k}, \mathrm{s}, \mathrm{y}]$} \\
\hline Particle width (mm), $w$ & & 4.1 & {$[\mathrm{k}, \mathrm{s}]$} & $2.1-2.9^{* *}, 2.5-3.6$ & {$[\mathrm{k}, \mathrm{s}]$} & $2.9-3.8$ & {$[\mathrm{k}, \mathrm{s}, \mathrm{y}]$} \\
\hline Particle thickness (mm), $h$ & & $2.8,3.4$ & {$[\mathrm{k}, \mathrm{s}]$} & $1.7-2.0^{* *}, 2.1-2.5$ & {$[\mathrm{k}, \mathrm{s}]$} & $2.2-3.0$ & {$[\mathrm{k}, \mathrm{s}, \mathrm{y}]$} \\
\hline Particle equivalent diameter $(\mathrm{mm}), d_{e}$ & & 3.5 & {$[\mathrm{k}]$} & $3.3-3.5$ & {$[\mathrm{k}]$} & $3.7-4.2$ & {$[\mathrm{k}]$} \\
\hline Particle radius $(\mathrm{mm}), r_{e}$ & & 1.8 & {$[\mathrm{k}]$} & $1.7-1.8$ & {$[\mathrm{k}]$} & $1.9-2.1$ & {$[\mathrm{k}]$} \\
\hline Particle mass (mg), $m$ & & $28-33.2$ & {$[\mathrm{k}, l, \mathrm{~s}]$} & $17.5-24.9^{* *}, 25-29.1$ & {$[\mathrm{k}, l, \mathrm{~s}]$} & $25.1-53.9$ & {$[\mathrm{k}, \mathrm{s}, \mathrm{y}, \mathrm{z}]$} \\
\hline Particle volume $\left(\mathrm{mm}^{3}\right), V$ & & 24.7 & {$[\mathrm{~s}]$} & $12-18^{* *}$ & {$[\mathrm{~s}]$} & $19.7-25.9$ & {$[\mathrm{~s}]$} \\
\hline Particle density $\left(\mathrm{kg} \mathrm{m}^{-3}\right), \rho_{p}$ & & $1220-1344$ & {$[\mathrm{k}, \mathrm{s}, \mathrm{z}]$} & $1382-1462,1110-1120,1360-1390$ & {$[\mathrm{k}, \mathrm{s}, \mathrm{z}]$} & $1130-1420$ & {$[\mathrm{k}, \mathrm{s}, \mathrm{y}, \mathrm{z}]$} \\
\hline Bulk density $\left(\mathrm{kg} \mathrm{m}^{-3}\right), \rho_{b}$ & & $643.5-775$ & {$[\mathrm{i}, \mathrm{k}, l, \mathrm{~s}, \mathrm{z}]$} & $641-851,579,573.2-579$ & {$[\mathrm{i}, \mathrm{k}, l, \mathrm{~s}, \mathrm{z}]$} & $566-691$ & {$[\mathrm{i}, \mathrm{k}, l, \mathrm{~s}, \mathrm{y}, \mathrm{z}]$} \\
\hline Particle Poisson ratio, $v$ & & -- & & -- & & $0.14-0.20$ & [y] \\
\hline Particle elastic modulus (MPa), $E$ & & -- & & -- & & $8.0-15.8$ & [y] \\
\hline Particle shear modulus (MPa), $G$ & & -- & & -- & & $3.3-6.87$ & [y] \\
\hline \multicolumn{8}{|l|}{ Particle restitution coefficient, $e$} \\
\hline Generic & & -- & & -- & & -- & \\
\hline With aluminum & & -- & & -- & & -- & \\
\hline With acrylic & & -- & & -- & & -- & \\
\hline \multicolumn{8}{|l|}{ Particle static friction coefficient, $\mu_{s}$} \\
\hline With self (grain) & & 0.65 & {$[\mathrm{~d}, \mathrm{k}]$} & $0.68^{*}, 0.73^{*}$ & {$[\mathrm{c}, \mathrm{d}, \mathrm{k}]$} & $0.51,0.53$ & {$[\mathrm{a}, \mathrm{d}, \mathrm{k}]$} \\
\hline With galvanized sheet (or sheet & metal) & -- & & $0.40-0.45^{*}$ & {$[\mathrm{c}, \mathrm{k}]$} & $0.17-0.352$ & {$[\mathrm{f}, \mathrm{k}, \mathrm{y}]$} \\
\hline With steel (or stainless steel) & & 0.37 & {$[\mathrm{~d}, \mathrm{k}]$} & $0.48^{*}$ & {$[\mathrm{~d}, \mathrm{k}]$} & $0.226-0.40$ & {$[a, d, e, k, y]$} \\
\hline With transparent perspex & & -- & & -- & & -- & \\
\hline With aluminum & & -- & & -- & & -- & \\
\hline With acrylic & & -- & & -- & & -- & \\
\hline With glass & & -- & & -- & & -- & \\
\hline \multicolumn{8}{|l|}{ Bulk angle of repose $\left(^{\circ}\right)$} \\
\hline $\begin{array}{l}\text { For filling or piling } \\
\quad \text { (also called dynamic angle) }\end{array}$ & & 20 & {$[\mathrm{~d}, \mathrm{k}]$} & $20^{*}$ & {$[\mathrm{~d}, \mathrm{k}]$} & 16 & {$[\mathrm{~d}, \mathrm{k}]$} \\
\hline $\begin{array}{l}\text { For emptying or funneling } \\
\text { (also called static angle) }\end{array}$ & & 33 & {$[\mathrm{~d}, \mathrm{k}]$} & $36^{*}$ & {$[\mathrm{~d}, \mathrm{k}]$} & 26.1-32.9 & {$[\mathrm{d}, \mathrm{k}, \mathrm{y}]$} \\
\hline [a] Airy (1898) & {$[\mathrm{k}] \mathrm{N}$} & Mohsenin (1986) & & [u] Watson (2003) & \multicolumn{3}{|c|}{ Unhulled seed or paddy } \\
\hline [b] Jamieson (1903) & {$[l] \mathrm{H}$} & Hoseney and Faubi & ion (1992) & [v] Chung et al. (2004) & \multicolumn{3}{|c|}{ ** Dehulled kernel } \\
\hline [c] Kramer (1944) & \multicolumn{3}{|c|}{ [m] Bilanski et al. (1994) } & [w] Raji and Favier $(2004 a, b)$ & & & \\
\hline [d] Stahl (1950) & \multicolumn{3}{|c|}{ [n] Shroyer et al. (1996) } & [x] Calisir et al. (2005) & & & \\
\hline [e] Lorenzen (1957) & \multicolumn{3}{|c|}{ [o] Gupta and Das (1997) } & [y] Molenda and Horabik (2005) & & & \\
\hline [f] Brubaker and Pos (1965) & \multicolumn{3}{|c|}{ [p] LoCurto et al. (1997a, b) } & [z] ASABE Standards (2006a) & & & \\
\hline [g] Arnold and Roberts (1969) & \multicolumn{3}{|c|}{ [q] Vu-Quoc et al. (2000) } & [aa] ASABE Standards (2006b) & & & \\
\hline [h] Shelef and Mohsenin (1969) & \multicolumn{3}{|c|}{ [r] McLelland and Miller (2001) } & [ab] Boyles et al. (2006) & & & \\
\hline [i] Henderson and Perry (1976) & \multicolumn{3}{|c|}{ [s] Nelson (2002) } & [ac] Chung and Ooi (2008) & & & \\
\hline [j] Misra and Young (1981) & \multicolumn{3}{|c|}{ [t] Zhang and Vu-Quoc (2002) } & & & & \\
\hline
\end{tabular}

\section{Particle Density}

Particle density $\left(\rho_{p}\right)$ of the grain is determined by measuring the volume occupied by the kernels in a known sample weight, randomly taken from each grain lot. Nelson (2002) measured the volume of an approximately 20 to $25 \mathrm{~g}$ sample with a Beckman model 930 air-comparison pycnometer. Kernel density was calculated by dividing the weighed mass by the measured volume.

\section{Particle Poisson's Ratio and Particle Shear Modulus}

Poisson's ratio $(v)$ is the absolute value of the ratio of transverse strain (perpendicular to the axis) to the corresponding axial strain (parallel to the longitudinal axis) resulting from uniformly distributed axial stress below the proportional limit of the material (Mohsenin, 1986). Based on Hooke's law and together with Poisson's ratio, shear modulus or modulus of rigidity $(G)$ for an elastic, homogenous, and isotropic material is the ratio of the stress component tan-

gential to the plane on which the forces acts (i.e., shear stress) over its strain. Shear modulus defined in terms of Poisson's ratio and Young's modulus or modulus of elasticity $(E)$ is given as follows (Mohsenin, 1986):

$$
G=\frac{E}{2+2 v}
$$

Several values of Poisson's ratio and elastic or Young's modulus for different grains and oilseeds were cited in the literature (table 1 ).

\section{Particle Coefficient of Restitution}

Different methods have been used to determine the coefficient of restitution, $e$ (Sharma and Bilanski, 1971; Smith and Liu, 1992; Yang and Schrock, 1994; LoCurto et al., 1997b). LoCurto et al. (1997b) described $e$ as the square root of the total kinetic energy before $\left(K E_{i}\right)$ and after $\left(K E_{r}\right)$ colli- 
Table 1 (continued). Range of published physical properties of grains and oilseeds.

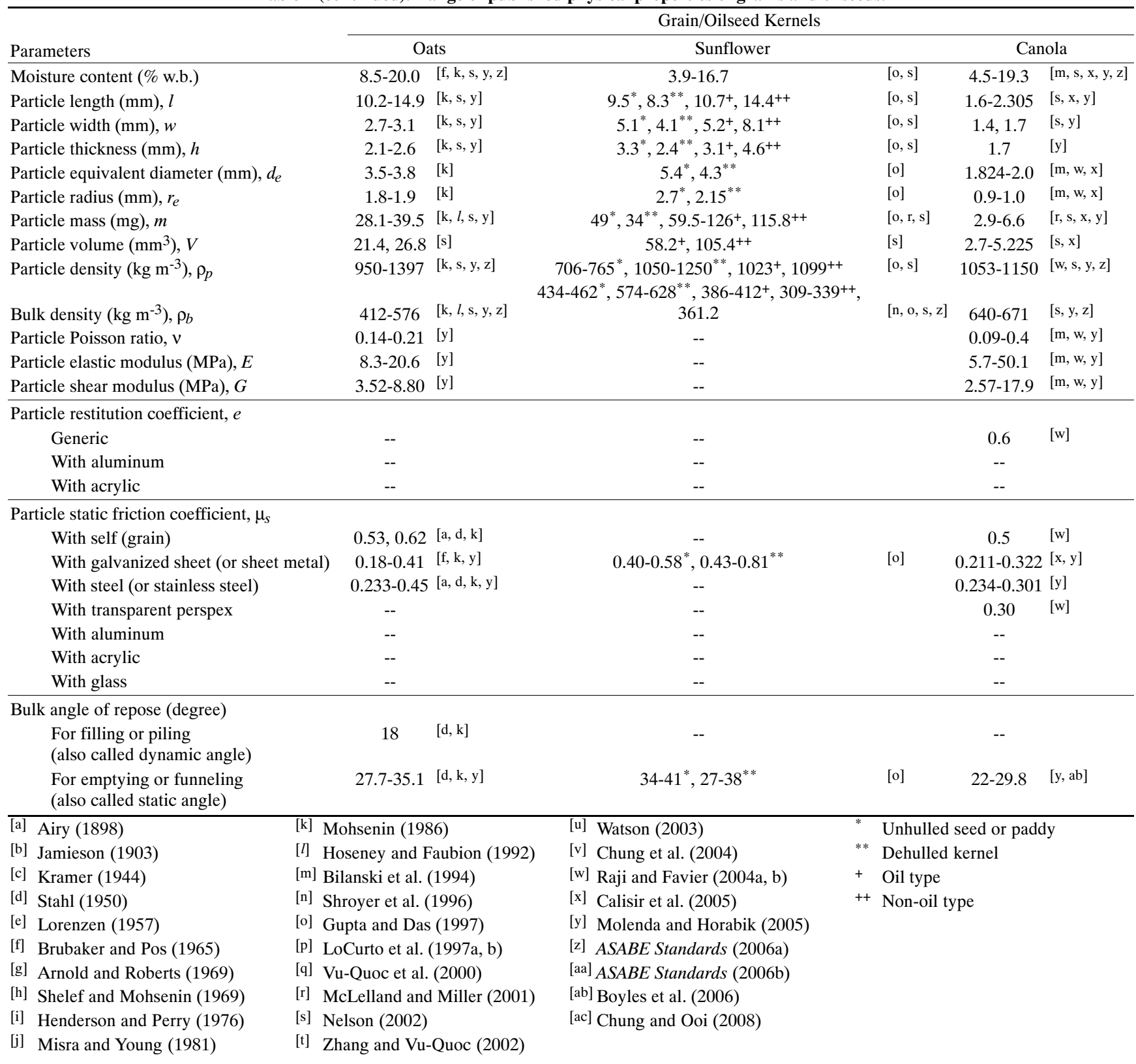

sions that did not involve tangential frictional losses. They measured $e$ values of soybeans impacting different surfaces at varying drop heights and moisture contents. The $e$ values decreased with increased moisture content and drop height, and contact with aluminum gave the highest value. Drop and rebound heights were measured only from those soybeans that fell with minimal rotation and whose rebound trajectories were almost vertical $(90 \% \pm 1.6 \%$ to the plate). This was different from the results of Yang and Schrock (1994), which involved cases of grain kernels with and without rotation. Assuming no loss of energy except during contact, the $e$ value was computed as the ratio of the square root of the initial height of drop $\left(H_{i}\right)$ and the height of rebound $\left(H_{r}\right)$ (LoCurto et al., 1997b; Zhang and Vu-Quoc, 2002):

$$
e \equiv\left(\frac{K E_{r}}{K E_{i}}\right)^{\frac{1}{2}} \equiv\left(\frac{H_{r}}{H_{i}}\right)^{\frac{1}{2}}
$$

\section{Particle Coefficient of Static Friction}

The coefficient of friction $(\mu)$ is the ratio of the force of friction $(F)$ to the force normal to the surface of contact $(W)$. Frictional forces acting between surfaces at rest with respect to each other and those existing between surfaces in relative motion are, respectively, called forces of static and kinetic friction. Static and kinetic coefficients of friction can be denoted by $\mu_{s}$ and $\mu_{k}$, respectively (Mohsenin, 1986). Published coefficients of static friction of grain-on-grain and grain-onsurfaces such as sheet metal, stainless steel, acrylic, aluminum, and glass are listed in table 1 . Static friction of soybean-steel contact is $67 \%$ of that of soybean on itself (Stahl, 1950).

\section{Particle Coefficient of Rolling Friction}

The coefficient of rolling friction $\left(\mu_{r}\right)$ is defined as the ratio of the force of friction to the force normal to the surface of contact that prevents a particle from rolling. Rolling fric- 
tion or resistance can be a couple (or pure moment) that may be transferred between the grains via the contacts, and this couple resists particle rotations (Jiang et al., 2005) without affecting translation. It may exist even at contacts between cylindrical grains (Bardet and Huang, 1993). The concept of taking into account rolling resistance at particle contacts is an alternative approach in DEM modeling to establish contact laws related to particle rotation (Jiang et al., 2005), instead of using non-spherical particles to inhibit particle rolling and produce a realistic rolling behavior (Rothenburg and $\mathrm{Ba}-$ thurst, 1992; Sawada and Pradhan, 1994; Ting et al., 1995; Ullidtz, 1997; Thomas and Bray, 1999; Ng, 2001; Mirghasemi et al., 2002; Mustoe and Miyata, 2001). In the micromechanical model of Jiang et al. (2005), only the normal basic element, composed of a spring and dashpot in parallel with a divider series, contributes to rolling resistance at grain contact. Rolling resistance directly affects only the angular motion and not the translational motion of grains.

Zhou et al. (2002) investigated the effect of rolling friction on the angle of repose of coarse glass beads. They included coefficients of rolling friction with a base value of 0.05 (range: 0 to 0.1 ) on particle-to-particle contact and twice that value for particle-wall contact in their simulations. The authors found that increasing both rolling frictions increased the angle of repose. This is due to a large resistance force to the rotational motion of spheres providing an effective mechanism to consume the kinetic energy, stop the rotational motion, and lead to the formation of a "sand pile" with high potential energy (Zhou et al., 1999).

\section{Bulk Density}

Bulk density $\left(\rho_{b}\right)$ is the ratio of the mass to a given volume of a grain sample including the interstitial voids between the particles (Hoseney and Faubion, 1992; Gupta and Das, 1997). In the U.S., bulk density or test weight per bushel is the weight (in lb) per Winchester bushel $\left(2,150.42\right.$ in. $\left.{ }^{3}\right)$ as determined using an approved device (USDA GIPSA, 2004). The USDA GIPSA (2004) method involves allowing a sufficient amount of grain from a hopper, suspended two inches above, to overflow the test weight kettle; leveling the kettle by three full-length, zigzag motions with a stroker; and weighing the grain from the kettle with an appropriate scale. Several $\rho_{b}$ values for grains and oilseeds were found in the literature (table 1).

\section{Bulk Angle of Repose}

Bulk angle of repose $(\theta)$ is defined as the angle with the horizontal at which bulk granular materials will stand when piled (Mohsenin, 1986; Hoseney and Faubion, 1992). At least two angles of repose are commonly defined, namely the static angle of repose and the dynamic angle of repose. Various authors referred to the static and dynamic angles of repose as, respectively, angle of repose in emptying or funneling and angle of repose for filling or piling (Stahl, 1950; Caughey et al., 1951; Mohsenin, 1986). The dynamic angle of repose is generally smaller than the static angle of repose by at least $3^{\circ}$ to $10^{\circ}$ (Fowler and Wyatt, 1960).

It is generally believed that the emptying or static angle of repose and the angle of internal friction are approximately the same (Mohsenin, 1986; Walton, 1994). The angle of repose is a useful estimate of the internal angle of friction when cohesion is low (Lambe and Whitman, 1969) as for most free- flowing agricultural grains. Fowler and Chodziesner (1959) noted that when the "relative roughness factor" in their equation is equal to unity (i.e., materials are sliding over themselves) and is zero (i.e., smooth surface), the angle of repose is equal to the angle of friction and is independent of the diameter of the granular material.

Some factors affecting angle of repose include frictional forces generated by the grain flowing against itself, distribution of weight throughout the grain mass, and moisture content of the grain (Hoseney and Faubion, 1992). The angle of repose is also influenced by the friction coefficient between the particles and the material of the base plate, heap size, particle size and distribution, particle density, and vibration (Kalman et al., 1993).

There are several methods for measuring angle of repose. Three common methods mentioned in the literature are injection method, discharge method, and tilting method (Linoya et al., 1990; Kalman et al., 1993). Two common ways to implement the injection method are constant height and constant base (Fowler and Wyatt, 1960; Kalman et al., 1993; Fraczek et al., 2007). The discharge method is also called the emptying method (Fraczek et al., 2007). The revolving cylinder and tilting box are both used in the tilting method (Kramer, 1944; Train, 1958; Fowler and Wyatt, 1960; Burmistrova et al., 1963; Kalman et al., 1993). The revolving cylinder is also used for measuring the dynamic angle of repose (Train, 1958; Fowler and Wyatt, 1960; Kalman et al., 1993). Another method used for measuring dynamic angle of repose is the Brown and Richards (1959) method.

Fraczek et al. (2007) encountered problems in measuring angle of repose using injection and discharge methods. These methods are based on the assumption that the mounted granular slope acquires a cone shape, but results of experimental measurements often contradicted this assumption. Depending on the properties of the granular materials, the following deviations from the cone shape were usually observed: truncation of the top, and convexity and concavity of slope. The authors recommended using digital-image analysis for a more precise measurement of angle of repose. Deviations from the cone shape increased with increasing moisture content of the material, as was also noted by other authors (Horabik and Lukaszuk, 2000). However, the more spherical the materials, the more regular will be the cone that forms.

Zhou et al. (2002) found that the angle of repose of monosized coarse glass spheres is significantly affected by sliding and rolling frictions, particle size, and container thickness, but not density, Poisson's ratio, damping coefficient, or Young's modulus. The authors observed that the angle of repose increases with increasing rolling or sliding friction coefficients and with decreasing particle size or container thickness. However, container thickness larger than a critical value (about a 20-particle diameter) gives a constant angle of repose corresponding to a situation without any wall effects. This was shown by simulation results with periodic boundaries applied to opposite walls of the container. Periodic boundary conditions enable any particle leaving the domain in that direction to instantly re-enter on the opposite side (DEM Solutions, 2009), simulating infinite length in that direction and thereby eliminating wall friction. In addition, the effect of particle size was mainly the result of its effect on rolling friction and not on sliding friction. 
Table 2. Moisture-dependent properties of soybean kernels.

\begin{tabular}{|c|c|c|c|c|c|c|c|}
\hline \multirow[b]{2}{*}{ Parameters } & \multicolumn{7}{|c|}{ Moisture Content (\% w.b.) } \\
\hline & 6.9 & 7.0 & 7.1 & 8.0 & 8.1 & 9.7 & 9.8 \\
\hline Particle length (mm), $l$ & -- & -- & -- & $8.2^{[\mathrm{f}]}$ & -- & $7.3[\mathrm{e}]$ & -- \\
\hline Particle width (mm), $w$ & -- & -- & -- & $6.6^{[\mathrm{f}]}$ & -- & $6.1^{[\mathrm{e}]}$ & -- \\
\hline Particle thickness (mm), $h$ & -- & -- & -- & $5.6^{\mathrm{f}]}$ & -- & $5.5[\mathrm{e}]$ & -- \\
\hline Particle equivalent diameter $(\mathrm{mm}), d_{e}$ & -- & -- & -- & -- & -- & -- & -- \\
\hline Particle radius $(\mathrm{mm}), r_{e}$ & -- & -- & -- & -- & -- & -- & -- \\
\hline Particle mass (mg), $m$ & -- & -- & -- & $185.0^{[\mathrm{f}]}$ & -- & $149.0[\mathrm{e}]$ & -- \\
\hline Particle volume $\left(\mathrm{mm}^{3}\right), V$ & -- & -- & -- & -- & -- & -- & -- \\
\hline Particle density $\left(\mathrm{kg} \mathrm{m}^{-3}\right), \rho_{p}$ & $1180^{[\mathrm{g}]}$ & $1130^{[\mathrm{g}]}$ & -- & $1325.2^{[\mathrm{f}]}$ & -- & -- & -- \\
\hline Bulk density $\left(\mathrm{kg} \mathrm{m}^{-3}\right), \rho_{b}$ & -- & - & -- & $739 \pm 3^{[\mathrm{f}]}$ & -- & -- & -- \\
\hline Particle Poisson ratio, $v$ & -- & -- & -- & $0.15 \pm 0.02^{[\mathrm{f}]}$ & -- & $0.4134[\mathrm{e}]$ & -- \\
\hline Particle elastic modulus (MPa), $E$ & -- & -- & -- & $32.6 \pm 1.4[\mathrm{f}]$ & -- & $128.8[\mathrm{e}]$ & -- \\
\hline Particle shear modulus (MPa), $G=E /(2+2 v)$ & -- & -- & -- & $13.33-15.04[\mathrm{f}]$ & -- & $45.56[\mathrm{e}]$ & -- \\
\hline \multicolumn{8}{|l|}{ Particle restitution coefficient } \\
\hline With aluminum & -- & -- & -- & -- & -- & -- & -- \\
\hline With self (grain) & -- & -- & -- & -- & -- & -- & -- \\
\hline \multicolumn{8}{|l|}{ Particle static friction coefficient } \\
\hline With galvanized sheet metal & -- & -- & $0.21^{[b]}$ & $0.23-0.27[\mathrm{f}]$ & $0.21^{[b]}$ & -- & $0.18^{[\mathrm{b}]}$ \\
\hline With stainless steel & -- & -- & -- & $0.223-0.247^{[\mathrm{f}]}$ & -- & -- & -- \\
\hline With aluminum & -- & -- & -- & -- & -- & -- & -- \\
\hline With acrylic & -- & -- & -- & -- & -- & -- & -- \\
\hline With glass & -- & -- & -- & -- & -- & -- & -- \\
\hline \multicolumn{8}{|l|}{ Bulk angle of repose $\left(^{\circ}\right)$} \\
\hline $\begin{array}{l}\text { For emptying or funneling } \\
\text { (also called static angle) }\end{array}$ & -- & -- & -- & $32.5 \pm 0.5^{[\mathrm{f}]}$ & -- & -- & -- \\
\hline \multicolumn{8}{|l|}{$\begin{array}{l}\text { [a] Misra and Young (1981) } \\
\text { [b] Mohsenin (1986, p. 801); Brubaker and Pos } \\
\text { [c] LoCurto et al. (1997a, 1997b) } \\
\text { [d] Nelson (2002) } \\
\text { [e] Zhang and Vu-Quoc (2002) } \\
\text { [f] Molenda and Horabik (2005) } \\
\text { [g] ASABE Standards (2006a). }\end{array}$} \\
\hline
\end{tabular}

Published angles of repose of grains and oilseeds for filling or piling and for emptying or funneling were found in the literature (table 1).

\section{Modeling WITH DEM}

DEM is a numerical modeling technique that simulates dynamic motion and mechanical interactions of each particle using Newton's second law of motion and a forcedisplacement law. In DEM modeling, particle interactions are treated as a dynamic process, which assumes that equilibrium states develop whenever internal forces in the system balance (Theuerkauf et al., 2007). Contact forces and displacements of a stressed particle assembly are found by tracking the movement of individual particles. Newton's law of motion gives the relationship between particle motion and the forces acting on each particle. Particles interact only at contact points, with their motion independent of the other particles. The soft-sphere approach commonly used in DEM models allows the particles to overlap, giving realistic deformation at contact areas. These overlaps representing local deformation at contacts are small in comparison to the particle size. Force-displacement laws at the contacts are based on Hertzian contact theory (Mindlin, 1949; Mindlin and Deresiewicz, 1953; Tsuji et al., 1992; Di Renzo and Di Maio, 2004, 2005). Normal and tangential forces, velocities, and related parameters are described by appropriate equations from mechanics of particles (Tsuji et al., 1992; DEM Solutions, 2009; Remy et al., 2009).

Table 1 lists published values of the physical properties for soybean, corn, wheat, grain sorghum, rice, barley, oat, sunflower, and canola seeds. Table 2 lists the moisturedependent characteristics of soybeans, and table 3 is a summary of published and representative values of material and interaction properties of soybeans. Selected representative values of material properties (i.e., particle density, particle Poisson's ratio, and particle shear modulus) and interaction properties (i.e., particle coefficient of restitution and particle coefficient of static friction) were used as base values, which are used as inputs to DEM modeling. The DEM modeling software used was EDEM 2.1.2 (DEM Solutions, Lebanon, N.H.). A range of each of these five physical properties was investigated in DEM simulations of basic physical property tests, using four particle shapes.

In this study, DEM simulations were conducted with varying physical properties of soybean kernels, based on values in the literature, to find property combinations that gave simulation results that correlate well with measured bulk properties of soybeans while maintaining or improving computational speed. Thus, an appropriate particle model was established for DEM simulations of soybean handling operations.

The following input parameters were included: (1) particle coefficient of restitution, (2) particle coefficient of static friction, (3) particle coefficient of rolling friction, (4) particle size distribution (PSD), (5) particle shear modulus, and 
Table 2 (continued). Moisture-dependent properties of soybean kernels.

\begin{tabular}{|c|c|c|c|c|c|c|c|}
\hline \multirow[b]{2}{*}{ Parameters } & \multicolumn{7}{|c|}{ Moisture Content (\% w.b.) } \\
\hline & 10.0 & 10.7 & 12.2 & 13.0 & 13.4 & 15.5 & 16.7 \\
\hline Particle length (mm), $l$ & $7.0^{[\mathrm{d}]}$ & -- & -- & -- & $7.1^{[\mathrm{d}]}$ & -- & $7.3[\mathrm{~d}]$ \\
\hline Particle width (mm), $w$ & $6.6^{[\mathrm{d}]}$ & -- & -- & -- & $6.6^{[\mathrm{d}]}$ & -- & $6.7^{[\mathrm{d}]}$ \\
\hline Particle thickness (mm), $h$ & $5.7[\mathrm{~d}]$ & -- & -- & -- & $5.7[\mathrm{~d}]$ & -- & $5.9[\mathrm{~d}]$ \\
\hline Particle equivalent diameter $(\mathrm{mm}), d_{e}$ & -- & -- & -- & -- & -- & -- & -- \\
\hline Particle radius $(\mathrm{mm}), r_{e}$ & -- & -- & -- & -- & -- & -- & -- \\
\hline Particle mass (mg), $m$ & $167.6^{[\mathrm{d}]}$ & -- & -- & -- & $173.9[\mathrm{~d}]$ & -- & $189.5^{[\mathrm{d}]}$ \\
\hline Particle volume $\left(\mathrm{mm}^{3}\right), V$ & $134.1^{[\mathrm{d}]}$ & -- & -- & -- & $139.1^{[\mathrm{d}]}$ & -- & $152.8^{[\mathrm{d}]}$ \\
\hline Particle density $\left(\mathrm{kg} \mathrm{m}^{-3}\right), \rho_{p}$ & $1250^{[\mathrm{d}]}$ & -- & -- & -- & $1250^{[\mathrm{d}]}$ & -- & $1243^{[\mathrm{d}]}$ \\
\hline Bulk density $\left(\mathrm{kg} \mathrm{m}^{-3}\right), \rho_{b}$ & $723^{[\mathrm{d}]}$ & $876^{[c]}$ & -- & -- & $712^{[\mathrm{d}]}$ & $850[\mathrm{c}]$ & $705^{[\mathrm{d}]}$ \\
\hline Particle Poisson ratio, $v$ & $0.4[\mathrm{a}]$ & -- & -- & $0.4[\mathrm{a}]$ & -- & -- & -- \\
\hline Particle elastic modulus (MPa), $E$ & $176.9[\mathrm{a}]$ & -- & -- & $112.7^{[\mathrm{a}]}$ & -- & -- & -- \\
\hline Particle shear modulus (MPa), $G=E /(2+2 v)$ & $63.18^{[\mathrm{a}]}$ & -- & -- & $40.25^{[a]}$ & -- & -- & -- \\
\hline \multicolumn{8}{|l|}{ Particle restitution coefficient } \\
\hline With aluminum & -- & $0.7[\mathrm{c}]$ & -- & -- & -- & $0.6^{[\mathrm{c}]}$ & -- \\
\hline With self (grain) & -- & $0.267[\mathrm{c}]$ & -- & -- & -- & $0.339[\mathrm{c}]$ & -- \\
\hline \multicolumn{8}{|l|}{ Particle static friction coefficient } \\
\hline With galvanized sheet metal & -- & -- & $\left.0.20^{[\mathrm{b}}\right]$ & -- & -- & -- & -- \\
\hline With stainless steel & -- & -- & -- & -- & -- & -- & -- \\
\hline With aluminum & -- & $0.366,0.329[\mathrm{c}]$ & -- & -- & -- & $0.395,0.375[\mathrm{c}]$ & -- \\
\hline With acrylic & -- & $0.326,0.332[\mathrm{c}]$ & -- & -- & -- & $0.344,0.357[\mathrm{c}]$ & -- \\
\hline With glass & -- & $0.327,0.328^{[\mathrm{c}]}$ & -- & -- & -- & $0.344,0.359[\mathrm{c}]$ & -- \\
\hline \multicolumn{8}{|l|}{ Bulk angle of repose $\left(^{\circ}\right)$} \\
\hline $\begin{array}{l}\text { For emptying or funneling } \\
\text { (also called static angle) }\end{array}$ & -- & -- & -- & -- & -- & -- & -- \\
\hline $\begin{array}{l}\text { [a] Misra and Young (1981) } \\
\text { [b] Mohsenin (1986, p. 801); Brubaker and Pos } \\
\text { [c] LoCurto et al. (1997a, 1997b) } \\
\text { [d] Nelson (2002) } \\
\text { [e] Zhang and Vu-Quoc (2002) } \\
\text { [f] Molenda and Horabik (2005) } \\
\text { [g] ASABE Standards (2006a). }\end{array}$ & & & & & & & \\
\hline
\end{tabular}

(6) particle shape (i.e., particle composed of from one to four overlapping spheres). Table 4 lists the variations in input parameters and includes test combination codes for the parameters: (1st digit) particle coefficient of restitution, (2nd digit) particle coefficient of static friction, (3rd digit) particle coefficient of rolling friction, (4th digit) particle size distribution (PSD), and (5th digit) particle shear modulus.

The base value (represented by 1 in the test combination codes) of the particle coefficient of restitution was 0.6 , which is the mean of published values. The second and third $e$ values, which were 0.3 and 0.9 , respectively, were chosen as extreme values inclusive of the published range (from 0.5 to $0.7)$.

The base value of the particle coefficient of static friction on soybean-soybean contact was 0.55 , which was adapted from Stahl (1950) and Mohsenin (1986). The $\mu_{s}$ for soybeansteel interaction, which was adapted from the same authors, was computed to be $67 \%$ of the base value for soybeansoybean contact. This percentage was used every time the value of the $\mu_{s}$ for soybean-soybean contact was changed. The second and third $\mu_{s}$ values for soybean-soybean contact, which were 0.35 and 0.75 , respectively, were chosen to provide a useful test range.

For particle coefficient of rolling friction, the base value assumed in the simulation was 0.1 , which was twice that of Zhou et al. (2002) for coarse glass beads. The second and third $\mu_{r}$ values were 0.05 and 0.2 to cover a useful range of $\mu_{r}$ values inclusive of the base value.
For PSD, fixed or uniform size distribution was used as the base value; normal PSD with a standard deviation factor (SDF) of 0.2 was second; and normal PSD with SDF of 0.4 was third. The second SDF value (0.2) was obtained from the coefficient of variation of single-kernel mass from ten soybean lots (table 5). This SDF value was derived from mass distribution. To correctly use this SDF value based on mass in the particle size distribution, the SDF and mean factor were included in the simulation by volume and not by diameter, to correctly account for the cubic relation of volume (and mass) to length.

The base value for particle shear modulus was the mean of the published values (41.7 MPa). Typically, shear modulus values do not greatly affect results, but smaller values of shear modulus are known to reduce computational time (Chung and Ooi, 2008; Remy et al., 2009); thus, the variation of shear modulus was toward lower values. The second value chosen was the lowest limit of the range of published shear modulus for soybeans (13.8 MPa). The very low third value (1.04 MPa), computed using the particle Young's modulus (2.6 MPa) from Remy et al. (2009) and the base value of the particle Poisson's ratio for soybeans (0.25), was selected for the potential to significantly reduce computation times.

Table 6 shows the test combinations of the five parameters used with the 1-sphere particle shape. Simulations using test combination 11111 were performed with the 2-, 3-, and 4-sphere particle shapes.

Four particle shapes were evaluated to represent soybean kernels (fig. 1). Particle shape was defined using one to four 
Table 3. Published properties of soybeans and their selected representative values. Marked representative values (*) were used as base values in simulation.

\begin{tabular}{|c|c|c|c|c|}
\hline \multirow{2}{*}{$\begin{array}{l}\text { Parameters } \\
\text { Moisture content (\% w.b.) }\end{array}$} & \multicolumn{2}{|c|}{ Range } & \multicolumn{2}{|c|}{ Representative Value } \\
\hline & $6.9-16.7$ & {$[\mathrm{~b}, \mathrm{~d}, \mathrm{e}, \mathrm{f}, \mathrm{i}, \mathrm{j}, l, \mathrm{~m}]$} & -- & \\
\hline Particle length (mm), $l$ & $7.0-8.2$ & {$[\mathrm{~g}, \mathrm{i}, \mathrm{j}, l]$} & 7.6 & {$[\mathrm{~g}, \mathrm{i}, \mathrm{j}, l]$} \\
\hline Particle width (mm), w & $6.1-6.7$ & {$[\mathrm{~g}, \mathrm{i}, \mathrm{j}, l]$} & 6.4 & {$[\mathrm{~g}, \mathrm{i}, \mathrm{j}, l]$} \\
\hline Particle thickness (mm), $h$ & $5.5-5.9$ & {$[\mathrm{~g}, \mathrm{i}, \mathrm{j}, l]$} & 5.7 & {$[\mathrm{~g}, \mathrm{i}, \mathrm{j}, l]$} \\
\hline Particle equivalent diameter $(\mathrm{mm}), d_{e}$ & 6 & {$[\mathrm{e}, \mathrm{k}]$} & 6 & {$[\mathrm{e}, \mathrm{k}]$} \\
\hline Particle radius $(\mathrm{mm}), r_{e}$ & 3 & {$[\mathrm{e}, \mathrm{k}]$} & 3 & {$[\mathrm{e}, \mathrm{k}]$} \\
\hline Particle mass (mg), $m$ & $100-200$ & {$[\mathrm{~g}, \mathrm{~h}, \mathrm{i}, \mathrm{j}, l]$} & 150 & {$[\mathrm{~g}, \mathrm{~h}, \mathrm{i}, \mathrm{j}, l]$} \\
\hline Particle volume $\left(\mathrm{mm}^{3}\right), V$ & $134.1-152.8$ & [i] & 143.5 & [i] \\
\hline Particle density $\left(\mathrm{kg} \mathrm{m}^{-3}\right), \rho_{p}$ & $1130.0-1325.2$ & {$[\mathrm{i}, \mathrm{k}, l, \mathrm{~m}]$} & $1228^{*}$ & {$[\mathrm{i}, \mathrm{k}, l, \mathrm{~m}]$} \\
\hline Bulk density $\left(\mathrm{kg} \mathrm{m}^{-3}\right), \rho_{b}$ & $705.0-876.0$ & {$[\mathrm{c}, \mathrm{f}, \mathrm{i}, l, \mathrm{~m}]$} & 790.5 & {$[\mathrm{c}, \mathrm{f}, \mathrm{i}, l, \mathrm{~m}]$} \\
\hline Particle Poisson ratio, $v$ & $0.08-0.4134$ & {$[\mathrm{~d}, \mathrm{~g}, \mathrm{j}, \mathrm{k}, l]$} & $0.25^{*}$ & {$[\mathrm{~d}, \mathrm{~g}, \mathrm{j}, \mathrm{k}, l]$} \\
\hline Particle elastic modulus (MPa), $E$ & $31.2-176.9$ & {$[\mathrm{~d}, \mathrm{j}, \mathrm{k}, l]$} & 104.1 & {$[\mathrm{~d}, \mathrm{j}, \mathrm{k}, l]$} \\
\hline Particle shear modulus (MPa), $G=E /(2+2 v)$ & $13.8-63.2$ & {$[\mathrm{~d}, \mathrm{j}, \mathrm{k}, l]$} & $41.7^{*}$ & {$[\mathrm{~d}, \mathrm{j}, \mathrm{k}, l]$} \\
\hline \multicolumn{5}{|l|}{ Particle restitution coefficient, $e$} \\
\hline With self (grain) & -- & & $0.60 *$ & {$[\mathrm{f}, \mathrm{g}, \mathrm{k}]$} \\
\hline Generic & $0.5,0.7$ & {$[\mathrm{k}, \mathrm{g}]$} & -- & \\
\hline With aluminum & $0.6,0.7$ & [f] & -- & \\
\hline With steel & -- & & $0.60^{*}$ & {$[\mathrm{f}, \mathrm{g}, \mathrm{k}]$} \\
\hline \multicolumn{5}{|l|}{ Particle static friction coefficient, $\mu_{s}$} \\
\hline With self (grain) & $0.267,0.55$ & {$[a, e, g]$} & $0.55 *$ & {$[\mathrm{a}, \mathrm{e}]$} \\
\hline With galvanized sheet metal & $0.18-0.27$ & {$[\mathrm{~b}, \mathrm{e}, l]$} & -- & \\
\hline With steel & $0.223-0.247,0.37$ & {$[\mathrm{a}, \mathrm{e}, l]$} & $0.37^{*}$ & {$[\mathrm{a}, \mathrm{e}]$} \\
\hline With transparent perspex & 0.30 & {$[\mathrm{k}]$} & -- & \\
\hline With aluminum & $0.329,0.366$ & [f] & -- & \\
\hline With acrylic & $0.326,0.332$ & [f] & -- & \\
\hline With glass & $0.327,0.328$ & {$[\mathrm{f}, \mathrm{g}]$} & -- & \\
\hline \multicolumn{5}{|l|}{ Particle rolling friction coefficient } \\
\hline With self (grain) & -- & & $0.10^{*}$ & assume \\
\hline With steel & -- & & $0.10^{*}$ & assume \\
\hline \multicolumn{5}{|l|}{ Bulk angle of repose $\left({ }^{\circ}\right)$} \\
\hline For filling or piling (also called dynamic angle) & 16 & {$[\mathrm{a}, \mathrm{e}]$} & 16 & {$[\mathrm{a}, \mathrm{e}]$} \\
\hline For emptying or funneling (also called static angle) & $29-33$ & {$[\mathrm{a}, \mathrm{e}, l]$} & 31 & {$[\mathrm{a}, \mathrm{e}, l]$} \\
\hline [a] Stahl (1950) [f] & LoCurto et al. (1997a, 1997b) & & j] Zhang and $\mathrm{Vu}-\mathrm{Qu}$ & $(2002)$ \\
\hline [b] Brubaker and Pos (1965) & Vu-Quoc et al. (2000) & & k] Raji and Favier (2 & a, 2004b) \\
\hline [c] Henderson and Perry (1976) & 1] McLelland and Miller (2001) & & l] Molenda and Hor & $(2005)$ \\
\hline [d] Misra and Young (1981) & Nelson (2002) & & m] ASAE Standards & 06a) \\
\hline \multicolumn{5}{|l|}{ [e] Mohsenin (1986) } \\
\hline & Table 4. Variation of input para & meters. & & \\
\hline Parameter & $\begin{array}{cc}\text { Symbol } & \text { Bas } \\
\end{array}$ & Value (1) & Second Value (2) & Third Value (3) \\
\hline 1. Particle coefficient of restitution & $e$ & 0.60 & 0.30 & 0.90 \\
\hline \multicolumn{5}{|l|}{ 2. Particle coefficient of static friction } \\
\hline Soybean-soybean & $\mu_{s(\mathrm{so}-\mathrm{so})}$ & 0.55 & 0.35 & 0.75 \\
\hline Soybean-steel & $\mu_{s}$ (so-st) & 0.37 & 0.23 & 0.50 \\
\hline $\begin{array}{l}\text { 3. Particle coefficient of rolling friction } \\
\text { (soybean-soybean is assumed same as soybean-steel) }\end{array}$ & $\mu_{r}$ & 0.10 & 0.05 & 0.20 \\
\hline 4. Particle size distribution & PSD & or uniform & Normal & Normal \\
\hline Mean factor & MF & 1.0 & 1.0 & 1.0 \\
\hline Standard deviation factor & SDF & 0.0 & 0.20 & 0.40 \\
\hline 5. Particle shear modulus (MPa) & $G$ & 41.7 & 13.8 & 1.04 \\
\hline
\end{tabular}

overlapping spheres. Overlapping spheres allow the creation of complex particle shapes but require increased computation times because each sphere in the shape requires individual calculation at each time step (LoCurto et al., 1997b; Raji and Favier, 2004b). Thus, a 1-sphere geometry is desirable based on computation time if particle physics can be adequately addressed without a more complex shape. Geometry and dimension (length, width, and thickness) of the 4-sphere model were based on the soybean model of LoCurto et al. (1997b) and Vu-Quoc et al. (2000), with slight differences in dimension to fit soybeans' published base values for particle density and particle volume (table 3 ).

Table 7 shows basic physical properties of the four particle shapes and positions of their spheres employed in the simulation. The position of each sphere in the $x, y$, and $z$ directions composing a particle shape is needed to define the particle shape in the simulation. Positions of the 1-, 2-, and 3-sphere 
Table 5. Experimental data for standard deviation factor (SDF) for particle size distribution. [a]

\begin{tabular}{|c|c|c|c|c|c|c|c|c|}
\hline \multirow[b]{2}{*}{ Lot } & \multirow[b]{2}{*}{ Variety } & \multirow[b]{2}{*}{ Source } & \multirow[b]{2}{*}{ Location Planted } & \multirow{2}{*}{$\begin{array}{l}\text { Crop } \\
\text { Year }\end{array}$} & \multirow{2}{*}{$\begin{array}{c}\text { No. of } \\
\text { Kernels } \\
\text { Weighed }\end{array}$} & \multicolumn{2}{|c|}{$\begin{array}{c}\text { Single Kernel Mass } \\
(\mathrm{mg})\end{array}$} & \multirow{2}{*}{$\begin{array}{l}\mathrm{CV} \\
(\%)\end{array}$} \\
\hline & & & & & & Mean & SD & \\
\hline 1 & 9A411NRR & Kauffman Seeds & Reno County, Kansas & 2008 & 55 & 144.24 & 25.41 & 17.62 \\
\hline 2 & 9A385NRS & Kauffman Seeds & Reno County, Kansas & 2007 & 50 & 112.85 & 20.14 & 17.85 \\
\hline 3 & KS-5005sp & KSU Agronomy Farm & Riley County, Kansas & 2007 & 51 & 221.40 & 40.00 & 18.06 \\
\hline 4 & KS-3406RR & KSU Agronomy Farm & Riley County, Kansas & 2007 & 55 & 132.97 & 26.14 & 19.66 \\
\hline 5 & KS-4607 & KSU Agronomy Farm & Riley County, Kansas & 2007 & 51 & 157.34 & 31.16 & 19.80 \\
\hline 6 & KS-4702sp & KSU Agronomy Farm & Riley County, Kansas & 2007 & 56 & 122.64 & 26.12 & 21.29 \\
\hline 7 & Mixed (100 lb) & Manhattan Farmers Co-op & Northeastern Kansas & 2007 & 53 & 149.48 & 32.07 & 21.46 \\
\hline 8 & Mixed (7080 lb) & Manhattan Farmers Co-op & Northeastern Kansas & 2007 & 53 & 149.91 & 32.35 & 21.58 \\
\hline 9 & KS-5002N (4RL9542) & KSU Agronomy Farm & Riley County, Kansas & 2004 & 55 & 157.42 & 34.39 & 21.84 \\
\hline \multirow[t]{3}{*}{10} & KS-4103sp (4RL4976) & KSU Agronomy Farm & Riley County, Kansas & 2004 & 56 & 124.19 & 28.46 & 22.91 \\
\hline & & & & Mean & 53.50 & 147.24 & 29.62 & 20.21 \\
\hline & & & & $\mathrm{SD}$ & 2.22 & 30.27 & 5.57 & 1.88 \\
\hline
\end{tabular}

[a] An SDF value of 0.2 was taken from the mean coefficient of variation (CV) of individually weighed soybean kernels.

Table 6. Test combinations of input parameters. ${ }^{[a]}$

\begin{tabular}{|c|c|c|c|c|c|c|}
\hline \multirow[b]{2}{*}{$\begin{array}{l}\text { Particle } \\
\text { Shape }\end{array}$} & \multirow[b]{2}{*}{ Test } & \multicolumn{5}{|c|}{ Test Combinations } \\
\hline & & $\begin{array}{c}\text { Particle } \\
\text { Restitution } \\
\text { Coefficient }[\mathrm{b}]\end{array}$ & $\begin{array}{c}\text { Particle } \\
\text { Static Friction } \\
\text { Coefficient }[\mathrm{c}]\end{array}$ & $\begin{array}{c}\text { Particle } \\
\text { Rolling Friction } \\
\text { Coefficient }[\mathrm{d}]\end{array}$ & $\begin{array}{c}\text { Particle } \\
\text { Size } \\
\text { Distribution }[\mathrm{e}]\end{array}$ & $\begin{array}{c}\text { Particle } \\
\text { Shear } \\
\text { Modulus } \mathrm{f}]\end{array}$ \\
\hline \multirow[t]{11}{*}{ 1-sphere } & 1 & 1 & 1 & 1 & 1 & 1 \\
\hline & 2 & 2 & 1 & 1 & 1 & 1 \\
\hline & 3 & 3 & 1 & 1 & 1 & 1 \\
\hline & 4 & 1 & 2 & 1 & 1 & 1 \\
\hline & 5 & 1 & 3 & 1 & 1 & 1 \\
\hline & 6 & 1 & 1 & 2 & 1 & 1 \\
\hline & 7 & 1 & 1 & 3 & 1 & 1 \\
\hline & 8 & 1 & 1 & 1 & 2 & 1 \\
\hline & 9 & 1 & 1 & 1 & 3 & 1 \\
\hline & 10 & 1 & 1 & 1 & 1 & 2 \\
\hline & 11 & 1 & 1 & 1 & 1 & 3 \\
\hline 2-sphere & 12 & 1 & 1 & 1 & 1 & 1 \\
\hline 3-sphere & 13 & 1 & 1 & 1 & 1 & 1 \\
\hline 4-sphere & 14 & 1 & 1 & 1 & 1 & 1 \\
\hline
\end{tabular}

[a] Refer to table 4 for complete interpretation.

[b] 1 stands for $e=0.6,2$ stands for $e=0.3$, and 3 stands for $e=0.9$.

[c] 1 stands for $\mu_{s \text { (so-so) }}=0.55, \mu_{s}$ (so-st) $=0.37 ; 2$ stands for $\mu_{s \text { (so-so) }}=0.35, \mu_{\mathrm{s} \text { (so-st) }}=0.23$; and 3 stands for $\mu_{\mathrm{s} \text { (so-so) }}=0.75, \mu_{\mathrm{s} \text { (so-st) }}=0.50$.

[d] 1 stands for $\mu_{r}=0.1,2$ stands for $\mu_{r}=0.05$, and 3 stands for $\mu_{r}=0.2$.

[e] 1 stands for uniform particle size, 2 stands for normal PSD with standard deviation factor $(\mathrm{SDF})=0.2$, and 3 stands for normal PSD with SDF $=0.4$.

[f] 1 stands for $G=41.7 \mathrm{MPa}, 2$ stands for $G=13.8 \mathrm{MPa}$, and 3 stands for $G=1.04 \mathrm{MPa}$.

particle shapes were modified to match the volume and particle density of the 4-sphere particle shape.

Preliminary accuracy tests for the particle coefficient of restitution were performed for all test combinations by simulating the dropping of 50 soybean particles from a height of $151 \mathrm{~mm}$ onto a flat steel surface. The height was based on the drop tests of LoCurto et al. (1997b) for soybeans. Drop and rebound heights were extracted from the simulation only from those particles with rebound trajectories that were vertical, based on the criteria of LoCurto et al. (1997b). The simulated rebound heights were used to calculate particle coefficients of restitution. The calculated particle coefficients of restitution were compared to input coefficients of restitution, which gave an indication of the simulation accuracy.

\section{Bulk Density Test}

The bulk density test was based on the USDA GIPSA (2004) procedure for test-weight-per-bushel apparatus (fig. 2). Dimensions of the inside diameter and height of the kettle were $117.475 \mathrm{~mm}$ (4.625 in.) and $101.60 \mathrm{~mm}$ (4.0 in.), respectively. The test weight kettle was drawn in a computeraided design (CAD) software (DS SolidWorks Corp., Concord, Mass.) and imported to establish model geometries in the simulation software. The hopper above the kettle was also drawn with the standard $31.75 \mathrm{~mm}$ (1.25 in.) opening and a standard distance from the kettle of $50.8 \mathrm{~mm}$ (2.0 in.) (USDA GIPSA, 1996).

Particles coming from the hopper dropped to fill the kettle. Excess particles were allowed to overflow. Simulation time for each test combination was between 20 to $120 \mathrm{~s}$, depending on the time the kettle was filled and the particles stopped flowing. Simulation time was determined by the particles stabilizing on top of the kettle and the kinetic energy of the whole system approaching zero.

To determine the bulk density $\left(\rho_{b}, \mathrm{~kg} \mathrm{~m}^{-3}\right)$, only the total mass of particles filling the kettle $\left(m_{p}, \mathrm{~kg}\right)$ was computed from the simulation. The mass of piled particles on top and 


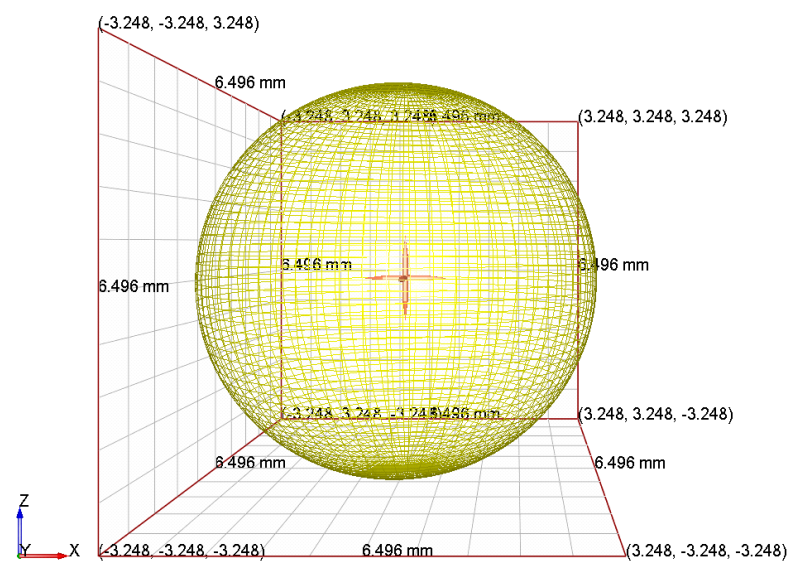

(a)

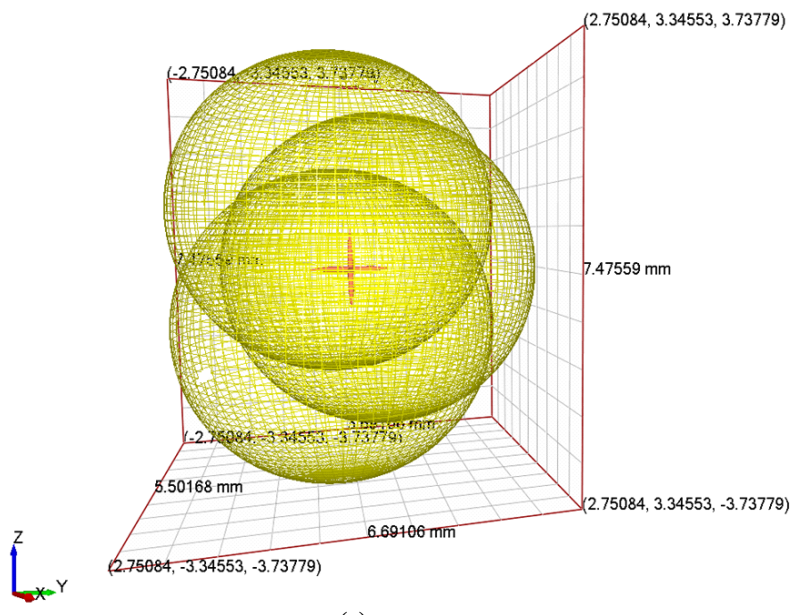

(c)

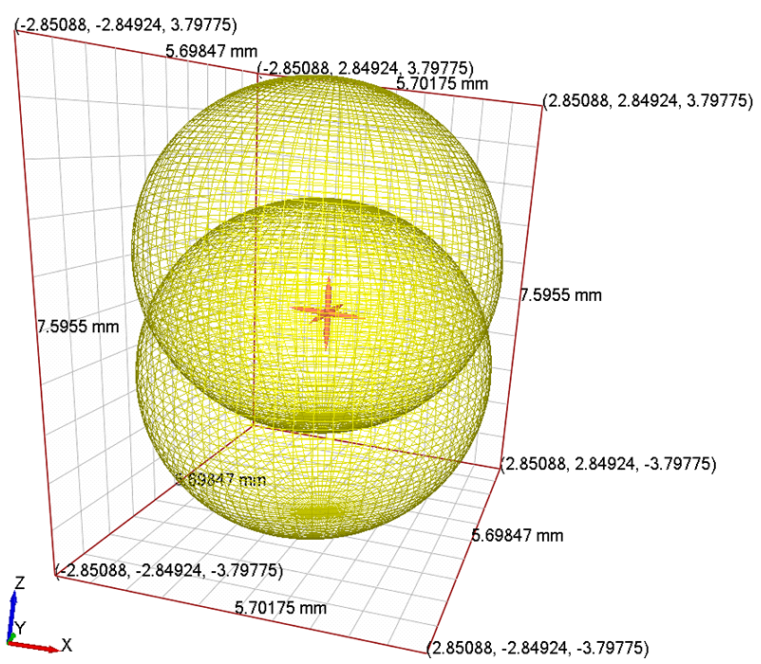

(b)

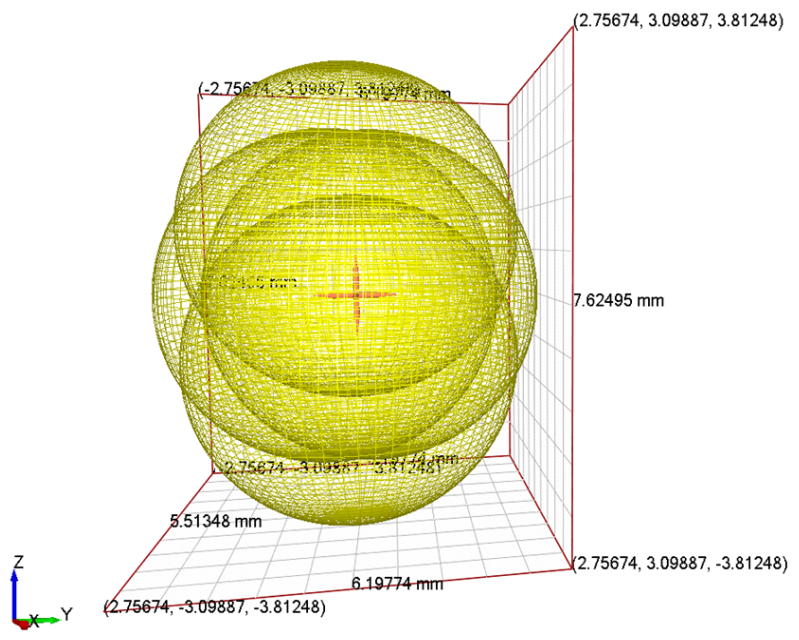

(d)

Figure 1. Particle shapes of soybean in the simulation: (a) 1-sphere model, (b) 2-sphere model, (c) 3-sphere model, and (d) 4-sphere model (drawn in EDEM Academic software).

Table 7. Properties of the four particle shapes or models and positions $(x, y, z)$ of each sphere in EDEM.

\begin{tabular}{|c|c|c|c|c|c|}
\hline \multirow[b]{2}{*}{ Parameter } & & \multicolumn{4}{|c|}{ Particle Shape } \\
\hline & & 1-Sphere & 2-Sphere & 3-Sphere & 4-Sphere \\
\hline Length of soybean ( $\mathrm{mm}$ ) & $l_{b}$ & 6.496 & 7.59550 & 7.47559 & 7.62495 \\
\hline Width of soybean (mm) & $w_{b}$ & 6.496 & 5.70175 & 6.69106 & 6.19774 \\
\hline Height of soybean (mm) & $h_{b}$ & 6.496 & 5.69847 & 5.50168 & 5.51348 \\
\hline Radius of sphere (mm), & $R$ & 3.248 & 2.85 & 2.75 & 2.75 \\
\hline Volume $\left(\mathrm{m}^{3}\right)$ & $V_{b}$ & $1.4350 \mathrm{E}-07$ & $1.4350 \mathrm{E}-07$ & $1.4350 \mathrm{E}-07$ & $1.4350 \mathrm{E}-07$ \\
\hline Mass (kg) & $m_{b}$ & 0.0001763 & 0.0001762 & 0.0001762 & 0.0001762 \\
\hline Particle density $\left(\mathrm{kg} \mathrm{m}^{-3}\right)$ & $\mu_{b}$ & 1228.0 & 1228.0 & 1228.0 & 1228.0 \\
\hline \multirow[t]{4}{*}{ Position $(x, y, z)$} & Surface 1 & $(0,0,0)$ & $(0,0,0)$ & $(0,0,0)$ & $(0,-0.35,0)$ \\
\hline & Surface 2 & -- & $(0,0,1.89)$ & $(0,0,1.975)$ & $(0,0.35,0)$ \\
\hline & Surface 3 & -- & -- & $(0,0.8,0.9875)$ & $(0,0,1.062)$ \\
\hline & Surface 4 & -- & -- & -- & $(0,0,-1.062)$ \\
\hline
\end{tabular}

outside of the kettle was excluded in the calculation. The calculated mass of particles inside the kettle was divided by the volume of the kettle $\left(V_{k}, \mathrm{~m}^{3}\right)$ to compute the bulk density, as shown in the following equation:

$$
\rho_{b}=\frac{m_{p}}{V_{k}}
$$

The mean bulk density for three replications for each test combination was also computed.

\section{Bulk Angle of Repose Test}

The tilting box method was employed to simulate the bulk angle of repose test of soybean particles in DEM (fig. 3). The tilting box method (Kramer, 1944; Burmistrova et al., 1963; 


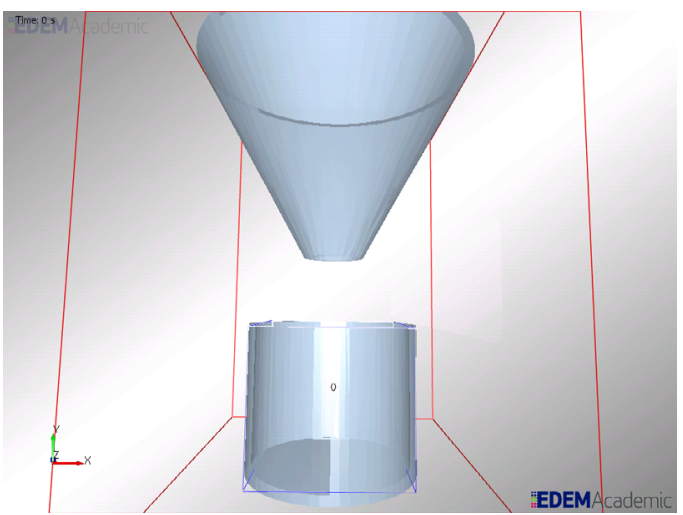

(a)

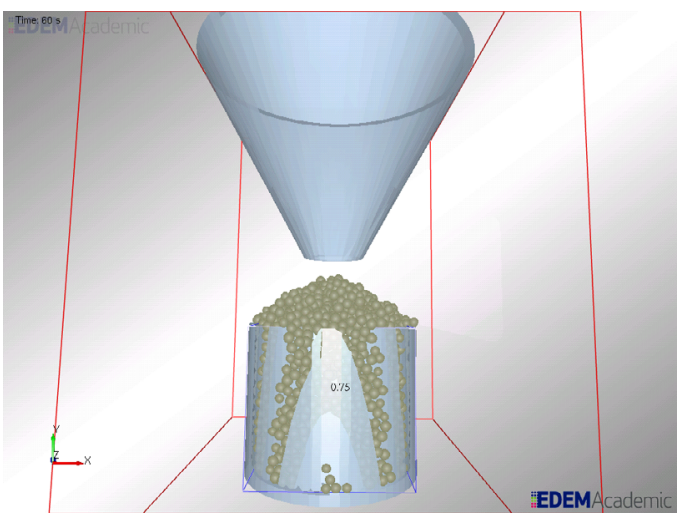

(b)

Figure 2. Bulk density tests in simulation: (a) empty test weight (TW) kettle and (b) full TW kettle.

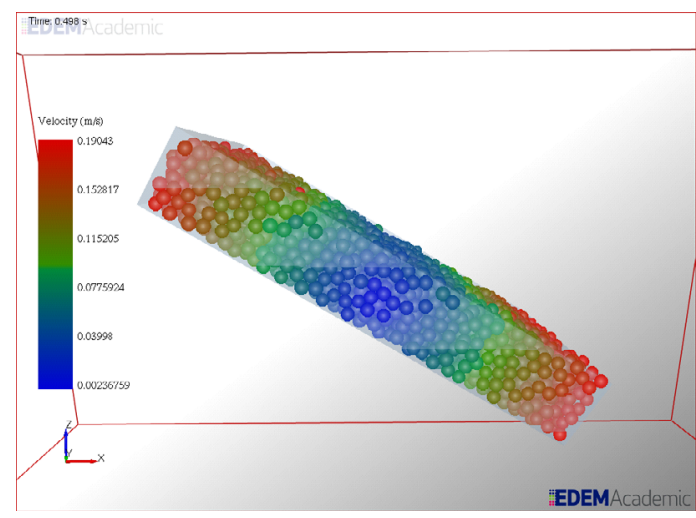

(a)

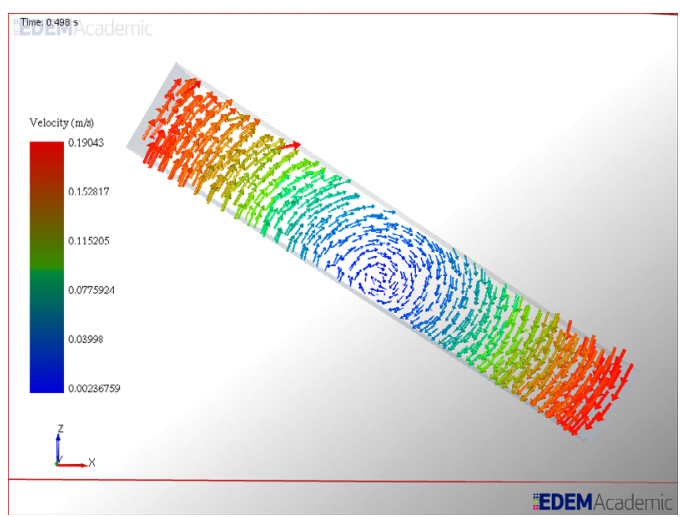

(b)

Figure 3. Bulk angle of repose test in simulation: (a) particle mode and (b) vector mode.

Train, 1958; Kalman et al., 1993), a static method, was chosen for DEM simulations of bulk angle of repose of soybean particles (fig. 3) because it is easier to model with the discrete element method than the alternatives. In addition, alternatives such as injection and discharge methods were avoided because of the problems and questions that arise when they are used (Fraczek et al., 2007; Kalman et al., 1993). A box measuring $240 \times 120$ $\times 40 \mathrm{~mm}$ was drawn and filled with soybean particles in the simulation. Train (1958) recommended that the width of the box be at least one-third of its length to reduce wall effects. In this simulation, the width was one-half of the length, which satisfied Train's recommendation.

Moreover, periodic boundaries were used on opposite sides of the simulation box (in the direction of the width = $120 \mathrm{~mm}$ ). Periodic boundary conditions enable any particle leaving the domain in that direction to instantly re-enter on the opposite side, simulating infinite length in that direction and, thereby eliminating wall friction. Base friction was also removed by ensuring that the base of the box had the same frictional coefficients as that of the particles.

After $0.15 \mathrm{~s}$ of filling the box up to the rim, the box was then tilted at a constant angular velocity $\left(\omega_{b}\right)$ of $90^{\circ} \mathrm{s}^{-1}$ until particles begin to move, and then the simulation was stopped after 0.65 to $0.85 \mathrm{~s}$ depending on the test combinations being evaluated. The time when the particles at the top layers began to move was recorded, $t_{\theta}$, which allowed calculation of the bulk angle of repose $(\theta)$ of the soybeans based on the angular velocity of the tilting box. The equation is given by:

$$
\theta=t_{\theta} \times \omega_{b}
$$

Both the individual particle motions and the vectors of the particle motions were evaluated to determine the start of particle movement. The mean bulk angle of repose for seven replications for each test combination was calculated.

\section{Data Analysis}

Mean, standard deviation, and percentage difference from expected input and published values were determined from the coefficient of restitution, bulk angle of repose, and bulk density tests. The simulation results were compared with the literature values based on their percentage differences. Test combinations having simulation results best correlating with the literature values were chosen to simulate soybeans in ongoing simulations of grain commingling.

\section{RESUlts AND Discussion}

In choosing the best particle model for soybeans, tradeoffs between the three criteria (bulk density, bulk angle of repose, and computation time) were required. The initial particle models were also revised by combining and refining input parameters that performed well in the initial tests. 
Table 8. Results of bulk density and bulk angle of repose tests for initial test combinations.

\begin{tabular}{|c|c|c|c|c|c|c|c|}
\hline \multirow[b]{2}{*}{ Parameter } & \multirow[b]{2}{*}{ Combination } & \multicolumn{3}{|c|}{ Bulk Density $\left(\mathrm{kg} \mathrm{m}^{-3}\right)$} & \multicolumn{3}{|c|}{ Bulk Angle of Repose $\left(^{\circ}\right)$} \\
\hline & & $\begin{array}{l}\text { Simulation } \\
\text { Value[a] }\end{array}$ & $\begin{array}{l}\text { Published } \\
\text { Value }\end{array}$ & $\begin{array}{c}\% \\
\text { Difference }\end{array}$ & $\begin{array}{l}\text { Simulation } \\
\text { Value[a] }^{\text {al }}\end{array}$ & $\begin{array}{l}\text { Published } \\
\text { Value }\end{array}$ & $\begin{array}{c}\% \\
\text { Difference }\end{array}$ \\
\hline \multirow[t]{3}{*}{ Restitution $[\mathrm{b}]$} & 1s_11111 $(e=0.6)$ & $669.00(1.60)$ & 720.72 & -7.18 & $31.50(0.35)$ & 31.0 & 1.61 \\
\hline & $1 \mathrm{~s} \_21111(e=0.3)$ & $660.39(0.77)$ & 720.72 & -8.37 & $32.31(0.82)$ & 31.0 & 4.23 \\
\hline & $1 s \_31111(e=0.9)$ & $687.12(0.93)$ & 720.72 & -4.66 & $37.17(0.47)$ & 31.0 & 19.91 \\
\hline \multirow[t]{3}{*}{ Static friction $[\mathrm{c}]$} & 1s_11111 $\left(\mu_{s}=0.55\right)$ & $669.00(1.60)$ & 720.72 & -7.18 & $31.50(0.35)$ & 31.0 & 1.61 \\
\hline & $1 \mathrm{~s} \_12111\left(\mu_{s}=0.35\right)$ & $678.30(2.00)$ & 720.72 & -5.89 & $31.50(1.25)$ & 31.0 & 1.62 \\
\hline & $1 \mathrm{~s} \_13111\left(\mu_{s}=0.75\right)$ & $665.67(3.03)$ & 720.72 & -7.64 & $37.35(1.47)$ & 31.0 & 20.49 \\
\hline \multirow[t]{3}{*}{ Rolling friction $[\mathrm{d}]$} & 1s_11111 $\left(\mu_{r}=0.1\right)$ & $669.00(1.60)$ & 720.72 & -7.18 & $31.50(0.35)$ & 31.0 & 1.61 \\
\hline & 1s_11211 $\left(\mu_{r}=0.05\right)$ & $680.08(0.33)$ & 720.72 & -5.64 & $30.52(0.50)$ & 31.0 & -1.54 \\
\hline & 1s_11311 $\left(\mu_{r}=0.2\right)$ & $656.61(0.72)$ & 720.72 & -8.89 & $35.28(0.98)$ & 31.0 & 13.81 \\
\hline \multirow[t]{3}{*}{ Size distribution $[\mathrm{e}]$} & 1s_11111 (SDF = 0) & $669.00(1.60)$ & 720.72 & -7.18 & $31.50(0.35)$ & 31.0 & 1.61 \\
\hline & 1s_11121 (SDF = 0.2) & $668.51(0.28)$ & 720.72 & -7.24 & $29.30(0.48)$ & 31.0 & -5.48 \\
\hline & 1s_11131 (SDF = 0.4) & $670.60(2.89)$ & 720.72 & -6.95 & $32.64(1.10)$ & 31.0 & 5.31 \\
\hline \multirow[t]{3}{*}{ Shear modulus ${ }^{[\mathrm{f}]}$} & 1s_11111 $(G=41.7 \mathrm{MPa})$ & $669.00(1.60)$ & 720.72 & -7.18 & $31.50(0.35)$ & 31.0 & 1.61 \\
\hline & 1s_11112 $(G=13.8 \mathrm{MPa})$ & $671.44(2.25)$ & 720.72 & -6.84 & $31.45(0.50)$ & 31.0 & 1.45 \\
\hline & $1 \mathrm{~s} \_11113(G=1.04 \mathrm{MPa})$ & $679.93(0.28)$ & 720.72 & -5.66 & $32.75(0.66)$ & 31.0 & 5.65 \\
\hline \multirow[t]{4}{*}{ Particle shape ${ }^{[g]}$} & 1s_11111 & $669.00(1.60)$ & 720.72 & -7.18 & $31.50(0.35)$ & 31.0 & 1.61 \\
\hline & 2s_11111 & $675.55(0.95)$ & 720.72 & -6.27 & $29.28(0.29)$ & 31.0 & -5.56 \\
\hline & 3s_11111 & $673.89(1.05)$ & 720.72 & -6.50 & $29.12(0.55)$ & 31.0 & -6.06 \\
\hline & 4s_11111 & $672.53(0.59)$ & 720.72 & -6.69 & $29.42(1.18)$ & 31.0 & -5.10 \\
\hline $\begin{array}{l}\text { [a] Values in parent } \\
\text { [b] 1st digit: } 1 \text { stand } \\
\text { [c] 2nd digit: } 1 \text { stan } \\
\text { [d] 3rd digit: } 1 \text { stanc } \\
\text { [e] 4th digit: } 1 \text { stand } \\
\text { and } 3 \text { stands for } \\
\text { [f] 5th digit: } 1 \text { stand } \\
\text { [g] 1s = 1-sphere, 2s }\end{array}$ & $\begin{array}{l}\text { es are standard deviations. } \\
\text { or } e=0.6,2 \text { stands for } e=0.2 \\
\text { or } \mu_{s} \text { (so-so) }=0.55, \mu_{s} \text { (so-st) } \\
\text { or } \mu_{r}=0.1,2 \text { stands for } \mu_{r}= \\
\text { or uniform particle size, } 2 \text { sta } \\
\text { mal PSD with SDF }=0.4 \text {. } \\
\text { or } G=41.7 \mathrm{MPa}, 2 \text { stands fo }\end{array}$ & $\begin{array}{l}\text { d } 3 \text { stands for } e \\
37 ; 2 \text { stands for } \\
\text { and } 3 \text { stands f } \\
\text { for normal PSD } \\
=13.8 \mathrm{MPa} \text {, and }\end{array}$ & $\begin{array}{l}9 . \\
\text {-so) }=0.35 \text {, } \\
=0.2 \text {. } \\
\text { standard d } \\
\text { ands for } G\end{array}$ & $\begin{array}{l}(\mathrm{so}-\mathrm{st})=0.23 \\
\text { ation factor } \\
.04 \mathrm{MPa} \text {. }\end{array}$ & $\begin{array}{l}\text { stands for } \mu_{s} \\
=0.2\end{array}$ & o) $=0.75, \mu_{s}$ & -st) $=0.50$ \\
\hline
\end{tabular}

In the preliminary accuracy tests, the input parameter was the particle coefficient of restitution, and the output calculated from the rebound height had the same particle coefficient of restitution values. All test combinations with the base particle coefficient of restitution of 0.6 had percent deviations ranging from $0.68 \%$ to $1.77 \%$. When the restitution coefficient was varied (cases 21111 and 31111), the percent deviation from the input value ranged from $0.25 \%$ to $7.6 \%$. The $0.25 \%$ deviation was obtained from the test combination with the highest particle coefficient of restitution (0.9), and the $7.6 \%$ deviation was from the combination with the lowest particle coefficient of restitution (0.3). Thus, only artificially low values of coefficient of restitution caused excessive accuracy issues, and these low values were not pursued further for the particle models.

\section{Bulk Density Test}

Bulk density increased with the coefficient of restitution but decreased with coefficients of static and rolling friction (table 8). Apparently, a high coefficient of restitution transfers more kinetic energy, so the impact tends to compact the particles in the kettle, leading to higher bulk density.

Wider size distributions increased bulk density, as observed from test combinations 11121 to 11131 . This may be explained by the increasing standard deviation factor (from 0.2 to 0.4 ) in the particle size distribution, which increases the smaller particles in the normal size distribution. These small particles were filling the voids between large particles, thereby increasing the bulk density.

Simulations involved fixed particle size within each particle shape. Particle density and mass were constant among particle shapes. Results showed that bulk density decreased as the number of spheres in a particle shape increased, except for the case of 1-sphere particle shape. This is likely because a 4-sphere particle shape occupies a slightly higher volume than a 2-sphere particle shape, which creates more void spaces in the kettle and slightly decreases the bulk density.

In general, the simulations resulted in lower bulk densities than the published values. Test combinations 31111, 12111, 11211, 11131, and 11113 for 1-sphere particle shape and 11111 for 2-sphere particle shape gave bulk densities closer to the literature value of $720.72 \mathrm{~kg} \mathrm{~m}^{-3}$.

\section{Bulk Angle of Repose Test}

Static and rolling friction coefficients affect the bulk angle of repose. In general, as the static and rolling friction coefficients increased so did the bulk angle of repose in the simulation (table 8). This observation was similar to that of Zhou et al. (2002) and Walton (1994).

The greater the number of spheres in a particle model, the higher the bulk angle of repose. Walton and Braun (1993) and Walton (1994) found increasing values of dynamic angle of repose as spheres increased from mono to cubic (8-sphere). Simulation results of static angle of repose, however, did not exactly agree with those authors' findings. This was likely due to the constant volume of the four particle models tested in the simulation, which generated almost the same particle size even though the number of spheres in a particle model increased, unlike the previous authors observed. The 1-sphere particle shape showed a very high bulk angle of repose, whereas the 3-sphere particle shape gave the lowest angle. The 4-sphere particle shape had a higher bulk angle of 
Table 9. Results of bulk density and bulk angle of repose tests for possible best test combination.

\begin{tabular}{|c|c|c|c|c|c|c|}
\hline \multirow[b]{2}{*}{ Combination } & \multicolumn{3}{|c|}{ Bulk Density $\left(\mathrm{kg} \mathrm{m}^{-3}\right)$} & \multicolumn{3}{|c|}{ Bulk Angle of Repose $\left(^{\circ}\right)$} \\
\hline & $\begin{array}{l}\text { Simulation } \\
\text { Value[a] }\end{array}$ & $\begin{array}{l}\text { Expected } \\
\text { Value }\end{array}$ & $\begin{array}{c}\% \\
\text { Difference }\end{array}$ & $\begin{array}{l}\text { Simulation } \\
\text { Value[a] }\end{array}$ & $\begin{array}{l}\text { Expected } \\
\text { Value }\end{array}$ & $\begin{array}{c}\% \\
\text { Difference }\end{array}$ \\
\hline \multicolumn{7}{|l|}{ Second iteration $[\mathrm{b}]$} \\
\hline 1s_12233 $\left(\mu_{s}=0.35\right)$ & $697.90(1.76)$ & 720.7 & -3.17 & $28.54(0.58)$ & 31.0 & -7.94 \\
\hline $1 \mathrm{~s} \_11231\left(\mu_{s}=0.55, G=41.7 \mathrm{MPa}\right)$ & $682.37(1.50)$ & 720.7 & -5.32 & $31.54(0.53)$ & 31.0 & 1.74 \\
\hline $1 \mathrm{~s} \_11232\left(\mu_{s}=0.55, G=13.8 \mathrm{MPa}\right)$ & $682.47(1.58)$ & 720.7 & -5.31 & $32.15(0.72)$ & 31.0 & 3.70 \\
\hline $1 \mathrm{~s} \_11233\left(\mu_{s}=0.55, G=1.04 \mathrm{MPa}\right)$ & $685.09(5.65)$ & 720.7 & -4.94 & $31.90(0.68)$ & 31.0 & 2.90 \\
\hline $1 \mathrm{~s} \_14231\left(\mu_{s}=0.58, G=41.7 \mathrm{MPa}\right)$ & $680.74(1.64)$ & 720.7 & -5.55 & $33.14(0.40)$ & 31.0 & 6.90 \\
\hline $1 \mathrm{~s} \_14232\left(\mu_{s}=0.58, G=13.8 \mathrm{MPa}\right)$ & $681.77(1.27)$ & 720.7 & -5.40 & $31.03(0.48)$ & 31.0 & 0.11 \\
\hline $1 \mathrm{~s} \_14233\left(\mu_{s}=0.58, G=1.04 \mathrm{MPa}\right)$ & $690.47(0.60)$ & 720.7 & -4.20 & $33.45(1.01)$ & 31.0 & 7.90 \\
\hline $1 \mathrm{~s} \_41111(e=0.7)$ & $671.77(1.36)$ & 720.7 & -6.79 & & & \\
\hline 1s_51111 $(e=0.8)$ & $679.45(0.68)$ & 720.7 & -5.73 & & & \\
\hline \multicolumn{7}{|l|}{ Third iteration $[\mathrm{b}]$} \\
\hline 1s_12233 $\left(\mu_{s}=0.35\right)$ & $697.90(1.76)$ & 720.7 & -3.17 & $28.54(0.58)$ & 31.0 & -7.94 \\
\hline $1 s \_17233\left(\mu_{s}=0.40\right)$ & $695.39(0.83)$ & 720.7 & -3.51 & $29.01(0.36)$ & 31.0 & -6.42 \\
\hline $1 s \_16233\left(\mu_{s}=0.45\right)$ & $693.73(1.15)$ & 720.7 & -3.74 & $30.89(0.53)$ & 31.0 & -0.36 \\
\hline $1 \mathrm{~s} \_15233\left(\mu_{s}=0.50\right)$ & $693.58(1.82)$ & 720.7 & -3.77 & $31.20(0.45)$ & 31.0 & 0.66 \\
\hline $1 \mathrm{~s} \_11233\left(\mu_{s}=0.55\right)$ & $685.09(5.65)$ & 720.7 & -4.94 & $31.90(0.68)$ & 31.0 & 2.90 \\
\hline 1s_14233 $\left(\mu_{s}=0.58\right)$ & $690.47(0.60)$ & 720.7 & -4.20 & $33.45(1.01)$ & 31.0 & 7.90 \\
\hline
\end{tabular}

[a] Values in parentheses are standard deviations.

[b] Particle shape: $1 \mathrm{~s}=1$-sphere.

Particle coefficient of restitution: 1 stands for $e=0.6,4$ stands for $e=0.7$, and 5 stands for $e=0.8$.

Particle coefficient of static friction: 1 stands for $\mu_{s \text { (so-so) }}=0.55, \mu_{s}$ (so-st) $=0.37 ; 2$ stands for $\mu_{s}$ (so-so) $=0.35$, $\mu_{s}$ (so-st) $=0.23 ; 4$ stands for $\mu_{s}$ (so-so) $=0.58$,

$\mu_{s \text { (so-st) }}=0.39 ; 5$ stands for $\mu_{s}$ (so-so) $=0.50, \mu_{s}$ (so-st) $=0.34 ; 6$ stands for $\mu_{s}$ (so-so) $=0.45$, $\mu_{s}$ (so-st) $=0.30$; and 7 stands for $\mu_{s}$ (so-so) $=0.40, \mu_{s}$ (so-st) $=0.27$.

Particle coefficient of rolling friction: 1 stands for $\mu_{r}=0.1$, and 2 stands for $\mu_{r}=0.05$.

Particle size distribution (PSD): 1 stands for uniform particle size, and 3 stands for normal PSD with SDF $=0.4$.

Particle shear modulus: 1 stands for $G=41.7 \mathrm{MPa}, 2$ stands for $G=13.8 \mathrm{MPa}$, and 3 stands for $G=1.04 \mathrm{MPa}$.

repose than the 2-sphere shape, which agreed with the published trend of Walton's group (table 8).

Bulk angle of repose increased for wider size distribution (i.e., from PSD with SDF $=0.2$ to that with $\mathrm{SDF}=0.4$ ). This result for static angle agreed with the experimental findings of Zenz (1957) for dynamic angle of repose.

For 1-sphere particle models, test combinations 11111, $12111,11211,11131$, and 11112 gave closer values to the published bulk angle of repose $\left(31^{\circ}\right)$. For multi-sphere particle models, results of test combination 11111 for the 4-sphere shape were closest to the published angles of repose. This test combination, however, did not vary much from test combination 11111 for 2- and 3-sphere shapes.

\section{Best-Correlated Particle Models}

In general, multi-sphere particle shapes did not give promising results in the bulk property tests. During initial testing (table 8), combination 31111 with the highest particle coefficient of restitution (0.9) resulted in the closest bulk density $\left(687.12 \mathrm{~kg} \mathrm{~m}^{-3}\right)$ to published values $\left(720.72 \mathrm{~kg} \mathrm{~m}^{-3}\right)$. However, the angle of repose of the bulk materials from this test combination $\left(37.17^{\circ}\right)$ was higher than the literature value $\left(31^{\circ}\right)$. The high bulk density may be explained by the high coefficient of restitution of the particle in the parameter mix of that test combination. A high coefficient of restitution transfers more kinetic energy, so the impact tends to compact the particles in the kettle, leading to high bulk density. The high density at which the particles are compacted fills the void spaces, which also led to a high angle of repose, as shown in the results in table 8 .

In a second iteration, modified testing was performed to determine whether lowering the particle coefficients of restitution (to 0.7 or 0.8 ) would result in a more desirable bulk angle of repose, yet still maintain bulk density close to the lit- erature value. Bulk density tests, including coefficients of restitution of 0.7 (test combination 4111) and 0.8 (test combination 5111), resulted in values of 671.77 and $679.45 \mathrm{~kg}$ $\mathrm{m}^{-3}$, respectively (table 9). These values, however, were lower than the bulk density values of test combinations 11211 $\left(680.08 \mathrm{~kg} \mathrm{~m}^{-3}\right)$ and $11113\left(679.93 \mathrm{~kg} \mathrm{~m}^{-3}\right)$ from the initial testing (table 8); thus, they were not tested for bulk angle of repose. For bulk angle of repose, test combinations 11112 $\left(31.45^{\circ}\right)$ and $11211\left(30.52^{\circ}\right)$ yielded values closest to the published value, with percent deviations of $1.45 \%$ and $-1.54 \%$, respectively.

With tradeoffs between bulk density and bulk angle of repose, test combination 11211 gave the best correlated coefficients of restitution, static friction, and rolling friction, which were $0.6,0.55$ (for soybean-soybean; 0.37 for soybean-steel), and 0.05 , respectively (table 8). However, test combination 11211 did not include size distribution of the particles because it only represented uniform or fixed particle sizes. Thus, the normal PSD with SDF of 0.4 was chosen because test combination 11131 performed better than 11121 in the bulk density and bulk angle of repose tests. For particle shear modulus, test combination $11113(G=1.04 \mathrm{MPa})$ did better in the bulk density test, while test combination $11112(G=$ $13.8 \mathrm{MPa}$ ) did best in the bulk angle of repose test (table 8). Both particle shear moduli were included in the second iteration, together with the highest shear modulus $(G=41.7 \mathrm{MPa})$, to determine how these shear moduli performed when combined with the other parameters (i.e., coefficients of restitution, rolling and static friction, and PSD). The second iteration also included the second particle coefficient of static friction of 0.35 (for soybean-soybean; 0.23 for soybeansteel), which was in 12111 due to this test combination's bulk density being higher than that of 11112 . 
Table 10. Effects of shear modulus and particle shape (number of spheres) on computational time.

\begin{tabular}{|c|c|c|c|c|c|}
\hline \multirow[b]{2}{*}{ Parameter } & \multirow[b]{2}{*}{ Combination } & \multicolumn{2}{|c|}{ Bulk Density Test } & \multicolumn{2}{|c|}{ Bulk Angle of Repose Test } \\
\hline & & $\begin{array}{l}\text { Computational } \\
\text { Time } \\
\text { [a] }\end{array}$ & $\begin{array}{l}\text { \% Time Diff. } \\
\text { from 1s_11111 }\end{array}$ & $\begin{array}{l}\text { Computational } \\
\text { Time }{ }^{[\mathrm{a}]}\end{array}$ & $\begin{array}{l}\text { \% Time Diff. } \\
\text { from 1s_11111 }\end{array}$ \\
\hline \multirow[t]{3}{*}{ Shear modulus $[\mathrm{b}]$} & 1s_11111 $(G=41.7 \mathrm{MPa})$ & $0.40(0.004)$ & 0.00 & $1.05(0.02)$ & 0.00 \\
\hline & 1s_11112 $(G=13.8 \mathrm{MPa})$ & $0.23(0.002)$ & -42.58 & $0.64(0.04)$ & -38.64 \\
\hline & $1 \mathrm{~s} \_11113(G=1.04 \mathrm{MPa})$ & $0.06(0.001)$ & -86.29 & $0.23(0.01)$ & -78.03 \\
\hline \multirow[t]{4}{*}{ Particle shape ${ }^{[b]}$} & 1s_11111 & $0.40(0.004)$ & 0.00 & $1.05(0.02)$ & 0.00 \\
\hline & 2s_11111 & $0.78(0.002)$ & 92.78 & $1.36(0.10)$ & 29.55 \\
\hline & 3s 11111 & $1.16(0.002)$ & 185.77 & $1.73(0.05)$ & 65.15 \\
\hline & 4s_11111 & $1.65(0.017)$ & 307.53 & $2.24(0.08)$ & 113.64 \\
\hline
\end{tabular}

[a] Actual hours per second in simulation time (values in parentheses represent standard deviations).

[b] Particle shape: $1 \mathrm{~s}=1$-sphere, $2 \mathrm{~s}=2$-sphere, $3 \mathrm{~s}=3$-sphere, and $4 \mathrm{~s}=4$-sphere.

Particle coefficient of restitution: 1 stands for $e=0.6$.

Particle coefficient of static friction: 1 stands for $\mu_{s \text { (so-so) }}=0.55, \mu_{s}$ (so-st) $=0.37$.

Particle coefficient of rolling friction: 1 stands for $\mu_{r}=0.1$.

Particle size distribution (PSD): 1 stands for uniform particle size.

Particle shear modulus: 1 stands for $G=41.7 \mathrm{MPa}, 2$ stands for $G=13.8 \mathrm{MPa}$, and 3 stands for $G=1.04 \mathrm{MPa}$.

In the second iteration, test combinations 12233 and 14233 , with particle coefficients of static friction of 0.35 and 0.58 , respectively, produced the best values for bulk density. The bulk angles of repose results, however, were poor for those combinations (table 9). A third iteration was performed using test combinations with particle coefficients of static friction between 0.35 and 0.58 . This iteration determined which particle coefficient of static friction would give the highest bulk density while maintaining the best possible value for bulk angle of repose. The third iteration revealed that the best parameter mix was test combination 16233, which included particle coefficients of restitution, static friction for soybean-soybean (soybean-steel), and rolling friction of 0.6, 0.45 (0.30), and 0.05 , respectively; PSD with SDF of 0.4; and particle shear modulus of $1.04 \mathrm{MPa}$ (table 9).

In addition, test combination 16233 reduced the computational time (Chung and Ooi, 2008; Remy et al., 2009) due to the low particle shear modulus $(G=1.04 \mathrm{MPa})$. The lowest shear modulus reduced computation time by $86 \%$ and $78 \%$, respectively, in bulk density and bulk angle of repose tests (table 10). Table 10 also shows the effect of particle shape; the smaller the number of spheres in a particle shape, the greater the time savings.

\section{SumMary AND CONClusion}

Material and interaction properties of various grains and oilseeds relevant to discrete element modeling (DEM) were reviewed. Material properties were particle shape and size, particle Poisson's ratio, particle shear modulus, and particle density. Interaction properties included particle coefficients of restitution, static friction, and rolling friction. Published values were used to establish base values for simulation modeling. Single- and multi-sphere soybean particle models, comprised of one to four overlapping spheres, were compared based on DEM simulations of two bulk properties: bulk density and bulk angle of repose.

A single-sphere particle model best simulated soybean kernels in the bulk property tests. The best particle model included a particle coefficient of restitution of 0.6 , particle coefficient of static friction of 0.45 for soybean-soybean contact ( 0.30 for soybean-steel interaction), particle coefficient of rolling friction of 0.05 , normal particle size distribution with a standard deviation factor of 0.4 , and particle shear modulus of 1.04 MPa. To optimize the simulated bulk properties, most parameters in this particle model varied only a small amount from the base values obtained from the literature. However, the particle shear modulus was set artificially low since that increased simulation speed without negatively impacting the simulation of bulk properties. This particle model will be used to simulate soybeans in grain handling and commingling studies in bucket elevator equipment.

\section{ACKNOWLEDGEMENTS}

The research was supported by the USDA (CRIS No. 5430-43440-005-00D) and Kansas Agricultural Experiment Station (Contribution No. 10-092-J). The technical advice of Dr. Oleh Baran (DEM Solutions), Dr. Christoph Hiemcke (formerly with DEM Solutions), Dr. Otis Walton (Grainflow Dynamics, Inc.), Dr. Ray Bucklin (University of Florida), and Dr. Jasper Tallada (USDA-ARS CGAHR) is highly appreciated. We also like to thank Dennis Tilley and Dr. Daniel Brabec (USDA-ARS CGAHR), Dr. William Schapaugh and Vernon Schaffer (KSU Agronomy Department), Dustin Miller and Tom Clayman (Kauffman Seeds), and the Manhattan Farmers Cooperative for soybean samples.

\section{REFERENCES}

Airy, W. 1898. The pressure of grain. In Minutes of Proc. of the Institution of Civil Engineers, 131: 347-358. J. H. T. Tudsbery, ed. London, U.K.: Institution of Civil Engineers.

Arnold, P. C., and A. W. Roberts. 1969. Fundamental aspects of load-deformation behavior of wheat grains. Trans. ASAE 12(1): 104-108.

ASABE Standards. 2006a. D241.4: Density, specific gravity, and mass-moisture relationships of grain for storage. St. Joseph, Mich.: ASABE.

ASABE Standards. 2006b. S368.4: Compression test of food materials of convex shape. St. Joseph, Mich.: ASABE.

Bardet, J. P., and Q. Huang. 1993. Rotational stiffness of cylindrical particle contacts. In Powders and Grains 93, 39-43. C. Thornton, ed. Rotterdam, The Netherlands: Balkema.

Berruto, R., and D. E. Maier. 2001. Analyzing the receiving operation of different grain types in a single-pit country elevator. Trans. ASAE 44(3): 631-638.

Bilanski, W. K., B. Szot, I. Kushwaha, and A. Stepneiwski. 1994. Comparison of strength features of rape pods and seeds for varieties cultivated in various countries. Intl. Agrophysics 8(4): 177-184. 
Boyles, M., T. Peeper, and M. Stamm. 2006. Great Plains Canola Production Handbook. MF-2734. Manhattan, Kansas: Kansas State University Cooperative Extension Service.

Brown, R. L., and J. C. Richards. 1959. Exploratory study of the flow of granules through apertures. Chem. Eng. Research and Design (Trans. Institution of Chem. Eng.) 37a: 108-119.

Brubaker, J. E., and J. Pos. 1965. Determining static coefficient of friction of grains on structural surfaces. Trans. ASAE 8(1): 53-55.

Burmistrova, M. F., I. K. Komol'kova, N. V. Klemm, M. T. Panina, I. M. Polunochev, A. I. P'yankov, A. F. Sokolov, N. G. Tetyanko, V. M. Chaus, and E. G. Eglit. 1963. Physicomechanical properties of agricultural crops. Translated from Russian and published for the National Science Foundation. Jerusalem: Israel: Program for Scientific Translations, Ltd.

Calisir, S., T. Marakoglu, H. Ogut, and O. Ozturk. 2005. Physical properties of rapeseed (Brassica napus oleifera L.). J. Food Eng. 69(1): 61-66.

Caughey, R. A., C. Tooles, and A. C. Scheer. 1951. Lateral and vertical pressures of granular materials in deep bins. Iowa Exp. Sta. Bulletin 172. Ames, Iowa: Iowa State University.

Chung, Y. C., and J. Y. Ooi. 2008. Influence of discrete element model parameters on bulk behavior of a granular solid under confined compression. Particulate Sci. and Tech. 26(1): 83-96.

Chung, Y. C., J. Y. Ooi, and J. F. Favier. 2004. Measurement of mechanical properties of agricultural grains for DE models. In Proc. 17th ASCE Engineering Mechanics Conf. Newark, Del.: American Society of Civil Engineers.

DEM Solutions. 2009. EDEM 2.1.2 User Guide. Lebanon, N.H.: DEM Solutions (USA), Inc.

Di Renzo, A., and F. P. Di Maio. 2004. Comparison of contact-force models for the simulation of collisions in DEM-based granular flow codes. Chem. Eng. Sci. 59(3): 525-541.

Di Renzo, A., and F. P. Di Maio. 2005. An improved integral non-linear model for the contact of particles in distinct element simulations. Chem. Eng. Sci. 60(5): 1303-1312.

Fowler, R. T., and W. B. Chodziesner. 1959. The influence of variables upon the angle of friction of granular materials. Chem. Eng. Sci. 10(3): 157-162.

Fowler, R. T., and F. A. Wyatt. 1960. The effect of moisture content on the angle of repose of granular solids. Australian J. Chem. Eng. 1: 5-8.

Fraczek, J., A. Zlobecki, and J. Zemanek. 2007. Assessment of angle of repose of granular plant material using computer image analysis. J. Food Eng. 83(1): 17-22.

Greenlees, W. J., and S. C. Shouse. 2000. Estimating grain contamination from a combine. ASAE Paper No. MC00103. St. Joseph, Mich.: ASAE.

Gupta, R. K., and S. K. Das. 1997. Physical properties of sunflower seeds. J. Agric. Eng. Res. 66(1): 1-8.

Hanna, H. M., D. H. Jarboe, and G. R. Quick. 2006. Grain residuals and time requirements for combine cleaning. ASABE Paper No. 066082. St. Joseph, Mich.: ASABE.

Henderson, S. M., and R. L. Perry. 1976. Agricultural Process Engineering. 3rd ed. Westport, Conn.: AVI Publishing.

Herrman, T. J., S. Baker, and F. J. Fairchild. 2001. Characterization of receiving systems and operating performance of Kansas grain elevators during wheat harvest. Applied Eng. in Agric. 17(1): $77-82$.

Herrman, T. J., M. A. Boland, K. Agrawal, and S. R. Baker. 2002. Use of a simulation model to evaluate wheat segregation strategies for country elevators. Applied Eng. in Agric. 18(1): 105-112.

Hirai, Y., M. D. Schrock, D. L. Oard, and T. J. Herrman. 2006. Delivery system of tracing caplets for wheat grain traceability. Applied Eng. in Agric. 22(5): 747-750.
Horabik, J., and J. Lukaszuk. 2000. Measurement of internal friction angle of wheat grain using triaxial compression test. Acta Agrophysica 37: 39-49 (in Polish).

Hoseney, R. C., and J. M. Faubion. 1992. Chapter 1: Physical properties of cereal grains. In Storage of Cereal Grains and Their Products. 4th ed. D. B. Sauer, ed. St. Paul, Minn.: American Association of Cereal Chemists.

Hurburgh, C. R., Jr. 1999. The GMO controversy and grain handling for 2000. Paper presented at the Iowa State University Integrated Crop Management Conference. Available at: https://www.extension.iastate.edu/NR/rdonlyres/3DA758C3-C1 36-456A-8062-53B08FA0BE00/82716/99gmoy2k.pdf. Accessed 2 July 2010.

Ingles, M. E. A., M. E. Casada, and R. G. Maghirang. 2003. Handling effects on commingling and residual grain in an elevator. Trans. ASAE 46(6): 1625-1631.

Ingles, M. E. A., M. E. Casada, R. G. Maghirang, T. J. Herrman, and J. P. Harner III. 2006. Effects of grain-receiving system on commingling in a country elevator. Applied Eng. in Agric. 22(5): 713-721.

Jamieson, J. A. 1903. Grain pressures in deep bins. Trans. Canadian Society of Civil Eng. 17(2): 554-607.

Jiang, M. J., H. S. Yu, and D. Harris. 2005. A novel discrete model for granular material incorporating rolling resistance. Computers and Geotech. 32(5): 340-357.

Kalman, H., D. Goder, M. Rivkin, and G. Ben-dor. 1993. The effect of the particle-surface friction coefficient on the angle of repose. Bulk Solids Handling 13(1): 123-128.

Kramer, H. A. 1944. Factors influencing the design of bulk storage bins for rough rice. Agric. Eng. 25(12): 463-466.

Lambe, T. W., and R. V. Whitman. 1969. Soil Mechanics. New York, N.Y.: John Wiley and Sons.

Li, Y., Y. Xu, and C. Thornton. 2005. A comparison of discrete element simulations and experiments for 'sandpiles' composed of spherical particles. Powder Tech. 160(3): 219-228.

Linoya, K., K. Gotoh, and K. Higashitani. 1990. Powder Technology Handbook. New York, N.Y.: Marcel Dekker.

LoCurto, G. J., V. Zakirov, R. A. Bucklin, D. M. Hanes, A. A. Teixeira, O. R. Walton, X. Zhang, and L. Vu-Quoc. 1997a. Soybean friction properties. ASAE Paper No. 974108. St. Joseph, Mich.: ASAE.

LoCurto, G. J., X. Zhang, V. Zarikov, R. A. Bucklin, L. Vu-Quoc, D. M. Hanes, and O. R. Walton. 1997b. Soybean impacts: Experiments and dynamic simulations. Trans. ASAE 40(3): 789-794.

Lorenzen, R. T. 1957. Effect of moisture content on mechanical properties of small grains. MS thesis. Davis, Cal.: University of California.

McLelland, M., and N. Miller. 2001. Using 1,000 kernel weight for calculating seeding rates and harvest losses. Edmonton, Alberta, Canada: Government of Alberta, Department of Agriculture and Rural Development. Available at: www1.agric.gov.ab.ca/ \$department/deptdocs.nsf/all/agdex81. Accessed 13 April 2007.

Mindlin, R. 1949. Compliance of elastic bodies in contact. Trans. ASME, J. Applied Mech. 16(3): 259-268.

Mindlin, R. D., and H. Deresiewicz. 1953. Elastic spheres in contact under varying oblique forces. Trans. ASME, Series E. J. Applied Mech. 20(3): 327-344.

Mirghasemi, A. A., L. Rothenburg, and E. L. Matyas. 2002. Influence of particle shape on engineering properties of assemblies of two-dimensional polygon-shaped particles. Geotechnique 52(3): 209-217.

Misra, R. N., and J. H. Young. 1981. A model for predicting the effect of moisture content on the modulus of elasticity of soybeans. Trans. ASAE 24(5): 1338-1341, 1347.

Mohsenin, N. N. 1986. Physical Properties of Plant and Animal Materials. 2nd ed. New York, N.Y.: Gordon and Breach Science.

Molenda, M., and J. Horabik. 2005. Part 1: Characterization of mechanical properties of particulate solids for storage and 
handling. In Mechanical Properties of Granular Agro-Materials and Food Powders for Industrial Practice. J. Horabik and J. Laskowski. eds. Lublin, Poland: Institute of Agrophysics Polish Academy of Sciences.

Mustoe, G. G. W., and M. Miyata. 2001. Material flow analyses of noncircular-shaped granular media using discrete element methods. J. Eng. Mech. 127(10): 1017-1026.

Nelson, S. O. 2002. Dimensional and density data for seeds of cereal grain and other crops. Trans. ASAE 45(1): 165-170.

$\mathrm{Ng}, \mathrm{T}$. T. 2001. Fabric evolution of ellipsoidal arrays with different particle shapes. J. Eng. Mech. 127(10): 994-999.

O'Sullivan, C., and J. D. Bray. 2004. Selecting a suitable time step for discrete element simulations that use the central difference time integration scheme. Eng. Comp. 21(2-4): 278-303.

Raji, A. O., and J. F. Favier. 2004a. Model for the deformation in agricultural and food particulate materials under bulk compressive loading using discrete element method: Part I. Theory, model development, and validation. J. Food Eng. 64(3): 359-371.

Raji, A. O., and J. F. Favier. 2004b. Model for the deformation in agricultural and food particulate materials under bulk compressive loading using discrete element method: Part II. Compression of oilseeds. J. Food Eng. 64(3): 373-380.

Remy, B., J. G. Khinast, and B. J. Glasser. 2009. Discrete element simulation of free-flowing grains in a four-bladed mixer. AIChE J. 55(8): 2035-2048.

Rothenburg, L., and R. J. Bathurst. 1992. Micromechanical features of granular assemblies with planar elliptical particles. Geotechnique 42(1): 79-95.

Sawada, S., and T. B. S. Pradham. 1994. Analysis of anisotropy and particle shape by distinct element method. In Computer Methods and Advancements in Geomechanics, 1: 665-670. H.

Siriwardane and M. M. Zaman, eds. Rotterdam, The Netherlands: Balkema.

Sharma, R. K., and W. K. Bilanski. 1971. Coefficient of restitution of grains. Trans. ASAE 14(2): 216-218.

Shelef, L., and N. N. Mohsenin. 1969. Effect of moisture content on mechanical properties of shelled corn. Cereal Chem. 46(3): 242-253.

Shroyer, J. P., P. D. Ohlenbusch, S. Duncan, C. Thompson, D. L. Fjell, G. L. Kilgore, R. Brown, and S. Staggenborg. 1996. Kansas crop planting guide. L-818. Manhattan, Kansas: Kansas State University Cooperative Extension Service.

Smith, C. E., and P. Liu. 1992. Coefficient of restitution. J. Applied Mech. 59(4): 963-969

Stahl, B. M. 1950. Grain bin requirements. Circular 835. Washington, D. C.: USDA.

Theuerkauf, J., S. Dhodapkar, and K. Jacob. 2007. Modeling granular flow using discrete element method: From theory to practice. Chem. Eng. 114(4): 39-46.

Thomas, P. A., and J. D. Bray. 1999. Capturing nonspherical shape of granular media with disk clusters. J. Geotech. and

Geoenviron. Eng. 125(3): 169-178.
Ting, J. M., L. R. Meachum, and J. D. Rowell. 1995. Effect of particle shape on the strength and deformation mechanism of ellipse-shaped granular assemblages. Eng. Comp. 12(2): 99-108.

Train, D. J. 1958. Some aspects of the property of angle of repose of powders. J. Pharmacy and Pharmacology 10(supp.): 127-135.

Tsuji, Y., T. Tanaka, and T. Ishida. 1992. Lagrangian numerical simulation of plug flow of cohesionless particles in a horizontal pipe. Powder Tech. 71(3): 239-250.

Ullidtz, P. 1997. Modelling of granular materials using the discrete element method. In Proc. 8th Intl. Conf. on Asphalt Pavements, 1: 757-769. Seattle, Wash.: University of Washington.

USDA GIPSA. 1996. Chapter 5: Test weight per bushel apparatuses. In Equipment Handbook. Washington, D.C.: USDA Grain Inspection, Packers, and Stockyards Administration.

USDA GIPSA. 2004. Book II: Grain grading procedures. In Grain Inspection Handbook. Washington, D.C.: USDA Grain Inspection, Packers, and Stockyards Administration.

Vu-Quoc, L., X. Zhang, and O. R. Walton. 2000. A 3-D discrete element method for dry granular flows of ellipsoidal particles. Computer Methods in Applied Mechanics and Eng. 187(3-4): 483-528.

Walton, O. R. 1994. Effects of interparticle friction and particle shape on dynamic angles of repose via particle-dynamic simulation. In Proc. Workshop on Mechanics and Statistical Physics of Particulate Materials, J. Jenkins and J. Goddard, eds. La Jolla, Cal.: Institute for Mechanics and Materials.

Walton, O. R., and R. L. Braun. 1993. Simulation of rotary-drum and repose tests for frictional spheres and rigid sphere clusters. In Proc. DOE/NSF Workshop on Flow of Particulates and Fluids. S. I. Plasynski, W. C. Peters, and M. C. Roco, eds. Ithaca, N.Y.: U.S. Department of Energy Pittsburgh Energy Technology Center, and National Science Foundation.

Watson, S. A. 2003. Chapter 3: Description, development, structure, and composition of the corn kernel. In Corn: Chemistry and Technology. P. J. White and L. A. Johnson, eds. St. Paul, Minn.: American Association of Cereal Chemists.

Wightman, C., M. Moakher, F. J. Muzzio, and O. R. Walton. 1998. Simulation of flow and mixing of particles in a rotating and rocking cylinder. AIChE J. 44(6): 1266-1276.

Yang, Y., and M. D. Schrock. 1994. Analysis of grain kernel rebound motion. Trans. ASAE 37(1): 27-31.

Zenz, F. A. 1957. How solid catalysts behave. Petroleum Refiner 36(4): 173-178.

Zhang, X., and L. Vu-Quoc. 2002. A method to extract the mechanical properties of particles in collision based on a new elasto-plastic, normal force-displacement model. Mechanics of Materials 34(12): 779-794.

Zhou, Y. C., B. D. Wright, R. Y. Yang, B. H. Xu, and A. B. Yu. 1999. Rolling friction in the dynamic simulation of sandpile formation. Physica A 269(2-4): 536-553.

Zhou, Y. C., B. H. Xu, A. B. Yu, and P. Zulli. 2002. An experimental and numerical study of the angle of repose of coarse spheres. Powder Tech. 125(1): 45-54. 